Discussion Paper No. 06-031

\title{
Rising Wage Dispersion, After All! \\ The German Wage Structure at the Turn of the Century
}

Karsten Kohn

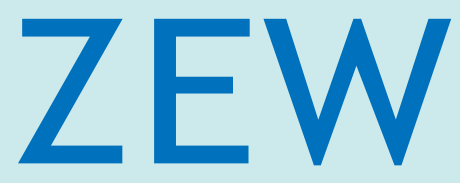

Zentrum für Europäische Wirtschaftsforschung $\mathrm{GmbH}$

Centre for European

Economic Research 
Discussion Paper No. 06-031

\title{
Rising Wage Dispersion, After All! The German Wage Structure at the Turn of the Century
}

\author{
Karsten Kohn
}

Download this ZEW Discussion Paper from our ftp server:

ftp://ftp.zew.de/pub/zew-docs/dp/dp06031.pdf

Die Discussion Papers dienen einer möglichst schnellen Verbreitung von neueren Forschungsarbeiten des ZEW. Die Beiträge liegen in alleiniger Verantwortung der Autoren und stellen nicht notwendigerweise die Meinung des ZEW dar.

Discussion Papers are intended to make results of ZEW research promptly available to other economists in order to encourage discussion and suggestions for revisions. The authors are solely responsible for the contents which do not necessarily represent the opinion of the ZEW. 


\section{Nontechnical Summary}

The German wage structure has been rather compressed in international comparison and "unbearabl[y] stable" (Prasad, 2000) between the mid-1970s and the mid-1990s. Newly available register data from the IAB employment sample 1975-2001 now allow to reinvestigate the empirical evidence for more recent years. This paper scrutinizes the evolution of wage levels and wage inequality within and between different labor market groups for the years 1992-2001. I find that wage inequality has in fact been rising in many dimensions throughout this period.

First, the inspection of year-specific wage distributions unveils that wage dispersion has been rising both in East and West Germany. The increase was more pronounced in East Germany such that, starting out from a lower degree in the year 1992, wage dispersion in the East largely caught with the West German level until 2001. The increase in wage inequality among women was more pronounced compared to the increase among men. Moreover, the larger part of the increase in dispersion among women happened in the lower parts of the distribution, but dispersion among men increased disproportionately in the upper parts. Convergence in wage levels between East and West Germany took place only up to the year 1996, but substantial differences persist since then.

Second, the estimation of censored quantile wage regressions provides insights into the determinants of the observed wage distributions. The bottom line of the regression results meets a-priori expectations: Age-earnings wage profiles not only are the steeper the higher the skill level, but they are also relatively flat in East Germany in 1992. The unification shock clearly led to a depreciation of human capital in the East. However, this effect wears out with the aging of post-unification labor market cohorts, and differences between East and West Germany have lessened by the year 2001.

Third, and finally, Machado/Mata (2005)-type analyses decompose differences across the wage distributions into a "characteristics effect", which captures differences in the composition of the workforce, and a "coefficients effect", which captures differences in the returns associated with observed characteristics. In East-West comparison, differences in the composition of the work force turn out largely negligible for men. However, characteristics of full-time working women are mostly in favor of higher wages in the East. Yet this effect ceases to apply at the lower end of the distribution by the year 2001. With respect to the evolution of wages over time, changes in the composition of the workforce capture major parts of the respective wage increases in the upper halves of the wage distributions for West Germany. This finding reflects a skill upgrading in the work force. Restructuring 
and skill upgrading yet played only a minor role in explaining the wage increases in East Germany. For women in the lower parts of the Eastern distribution, the characteristics effect even worked toward real wage cuts, substantiating the particular increase in wage dispersion among this group. 


\title{
Rising Wage Dispersion, After All! The German Wage Structure at the Turn of the Century
}

\author{
Karsten Kohn*
}

This Draft: April 18, 2006

\begin{abstract}
Using register data from the IAB employment sample, this paper studies the wage structure in the German labor market throughout the years 1992-2001. Wage dispersion has generally been rising. The increase was more pronounced in East Germany and occurred predominantly in the lower part of the wage distribution for women and in the upper part for men. Censored quantile wage regressions reveal diverse age and skill patterns. Applying Machado/Mata (2005)-type decompositions I conclude that differences in the composition of the work force only had a small impact on the observed wage differentials between East and West Germany, but changes in the characteristics captured better parts of the observed wage changes over time.
\end{abstract}

Key Words: Wage inequality, censored quantile regression, Machado/Mata decomposition, IABS, East Germany, West Germany.

JEL-Classification: J31, C24.

* Goethe-University Frankfurt and IZA. Correspondence: Goethe-University Frankfurt, Department of Economics, 60054 Frankfurt am Main, Germany. Email: kohn@wiwi.uni-frankfurt.de.

I thank Melanie Arntz, Martin Biewen, and Bernd Fitzenberger for fruitful discussions and participants of the workshop Wage Growth and Mobility: Micro-, Macro- and Intergenerational Evidence at the ZEW Mannheim for constructive comments on an earlier version. The responsibility for all errors is, of course, mine. 


\section{Introduction}

The structure of wages is crucial for economic performance and the evolution of employment in particular; see the handbook article of Katz and Autor (1999) and the more recent survey of Autor, Katz, and Kearney (2005b). With the growing availability of large micro data sets not only the wage level, but also the degree of wage dispersion or compression has received increasing attention. The evolution of the West German wage structure between the mid-1970s and the mid-1990s has been extensively studied. By and large, the wage structure has been found to be relatively compressed in international comparison and rather stable over time; see Fitzenberger (1999) and Prasad (2000) and the literature cited therein. Returns to human capital components as well as residual wage inequality showed fairly little variation. In face of an ongoing skill-biased technical change (Acemoglu, 2002), this "unbearable stability" (Prasad, 2000) is considered a key aspect for the growing unemployment among low-skilled workers and it is frequently attributed to institutional rigidities.

Studies of the East German wage structure report an even higher degree of wage compression in the late years of the GDR, reflecting the egalitarian doctrine of the socialist system; see Krueger and Pischke (1995). This finding of strong wage compression still holds for the early years after the German unification. Exceptionally flat age-earnings or experience-earnings profiles suggest that experience accumulated under the old system is poorly remunerated afterwards. The unification shock led to a massive depreciation of human capital. However, as post-unification labor market cohorts started to age, wage dispersion increased, catching up to the West German level; see Franz and Steiner (2000) and Burda and Hunt (2001).

More up-to-date data lately allow to trace the evolution of the wage structure toward the turn of the century. Recent evidence from survey data in Gernandt and Pfeiffer (2006) and from administrative data in Möller (2005) suggests that inequality has in fact been rising in both East and West Germany. In this paper, I employ the recently available regional file of the IAB employment sample (IABS) 1975-2001 for a comprehensive description of the structure of wages for different labor market groups in the first decade after the German unification.

An inspection of year-specific unconditional wage distributions for the different groups generally supports the notion of rising wage inequality. As measured by the interquintile range QD8020, in the year 1992 dispersion was lower in East Germany than in West Germany, but it was even higher by the year 2001. The increase was highest for full- 
time working women in East Germany, for whom QD8020 went up by remarkable 25 log percentage points. Moreover, the larger part of the increase in dispersion among women happened in the lower parts of the respective distributions. Dispersion among men increased disproportionately in the upper parts, though. Convergence in wage levels between East and West Germany has essentially not been achieved.

The subsequent analysis contributes to the literature by means of two approaches. First, I estimate wage equations in order to shed light on the determinants of observed wages. The large sample size of the IABS allows the application of quantile regression techniques, which are more flexible than the least squares estimations employed by most existing studies. Due to censoring of the wage data at the social security taxation threshold, I use censored quantile regressions (CQR). The bottom line of the regression results meets apriori expectations. Age-earnings profiles not only are the steeper the higher the skill level, but they are also relatively flat in East Germany in 1992. The effect of the unification shock in fact wears out with the aging of post-unification labor market cohorts, and differences in the profiles have lessened by the year 2001. The quantile regression approach reveals significant differences in the effects across the wage distribution. The result that low-skilled women working full-time in East Germany are left particularly worse-off at the lower end of the distribution substantiates the high and asymmetric increase in dispersion for this group.

Second, I employ the decomposition technique introduced by Machado and Mata (MM, 2005), which builds on the estimation of quantile regressions, in order to shed light on (1) differences of the wage distributions between East and West Germany and (2) changes of the wage structure over time. The MM decomposition is well-suited to depict heterogeneous characteristics and coefficients effects across the wage distribution. In East-West comparison, differences in the composition of the work force turn out to be largely negligible for men. However, characteristics of full-time working women are mostly in favor of higher wages in the East. Yet this effect ceases to apply at the lower end of the distribution in 2001. With respect to the evolution of wages over time, characteristics effects capture major parts of the respective wage increases in the upper half of the wage distribution for West Germany. This finding reflects a skill upgrading in the work force. Restructuring and skill upgrading yet played only a minor role in explaining the wage increases in East Germany. For women in the lower parts of the distribution the characteristics effect even worked toward real wage cuts, substantiating also the particular increase in wage dispersion among this group.

With these two approaches, the paper goes beyond the recent studies of Möller (2005) and 
Gernandt and Pfeiffer (2006) which also report rising wage dispersion in Germany. Using the IABS 2001, Möller compares raw decile ratios of wage distributions for some selective labor market groups, but he does not investigate into the nature of observed differences by means of regression or decomposition techniques. Gernandt and Pfeiffer do employ wage regressions and decompositions, but their analysis is restricted by the small sample size of the GSOEP survey data such that they do not run separate analyses for women and have to rely on OLS regressions and the decomposition technique introduced by Juhn, Murphy, and Pierce (1993). As it turns out in this paper below, the more flexible MM decompositions unveil important differences across the respective distributions.

The course of the paper is organized as follows. Section 2 starts out from related analyses of the German wage structure in the literature. It introduces the data at use and offers a snapshot of raw wage distributions for different labor market groups. Section 3 introduces the estimation approach and discusses estimation results. The particular focus is on differences in estimated coefficients for age and skill and on the shape of age-earnings profiles. Decomposition techniques for the setting at hand are introduced in section 4 . The subsequent discussion of results scrutinizes patterns in the respective wage distributions and discusses the effects underlying the wage differentials between East and West Germany as well as the changes of the wage structure over time. Section 5 concludes.

\section{Approaching the German Wage Structure}

The evolution of the West German wage structure between the mid-1970s and the mid1990s has been extensively studied since large micro data sets have become available. Studies used the survey data provided by the German Socio-Economic Panel (GSOEP) or the administrative IAB employment samples (IAB-Beschäftigtenstichproben, IABS). By and large, the wage structure has been found to be relatively compressed in international comparison and rather stable over time; see Fitzenberger (1999) and Prasad (2000) and the literature cited therein. Returns to human capital components such as skill and experience as well as residual wage inequality showed fairly little variation. In face of an ongoing skill-biased technical change (Acemoglu, 2002), this "unbearable stability" (Prasad, 2000) is considered a key aspect for the growing unemployment among lowskilled workers. Compression and stability is often attributed to institutional factors. However, some degree of variability is found by a few studies with more in-depth focus. For example, Riphahn (2003) reports higher income inequality among foreign workers, Fitzenberger (1999) reports some changes in the upper and in the lower parts of the wage 
structure, and when looking separately at different age groups Fitzenberger and Kohn (2005) find that there was quite some variation in the skill premia across age: cohort effects differently affected the different skill groups. Observed trends prove consistent with steady skill-biased technical change.

In their early study of the East German wage structure, Krueger and Pischke (1995) use the 1988 Survey on Income of Blue and White Collar Households in the GDR (Einkommensstichprobe in Arbeiter- und Angestelltenhaushalten) and the retrospective 1989 information of the 1990 GSOEP-East to find an even more compressed wage structure in the late years of the GDR, expressing the egalitarian doctrine of the socialist system. Follow-up comparative studies using different GSOEP waves ${ }^{1}$ confirm this effect for the first years after the German unification. In particular, they report flat age-earnings or experience-earnings profiles in the East. The findings suggest that experience accumulated under the old system is poorly remunerated afterwards. The unification shock led to a massive depreciation of human capital. However, as post-unification labor market cohorts start to age, increasing wage dispersion is observed in East Germany during the 1990s.

More up-to-date administrative data for both parts of the country have recently been made available with the regional file of the IAB employment sample (IABS) 1975-2001. This version of the IABS is a $2 \%$ random sample of German social security accounts; see Hamann et al. (2004) for a description of the data set. ${ }^{2}$ While excluding mainly self-employed workers and civil servants, the IABS covers about $80 \%$ of all employed persons. Employment in East Germany is included from 1992 onwards. The IABS offers a large sample size and - due to its administrative character - a reliable quality of data. In particular, the wage data are very accurate compared to survey data. On the downside, the data set provides relatively few covariates and no information on working time except from a distinction between full-timers and part-timers. Besides, the wage data are topcoded at the social security taxation threshold (SSTT).

\footnotetext{
${ }^{1}$ Schwarze and Wagner (1992), Schwarze (1993), and Bird, Schwarze, and Wagner (1994) also use the retrospective information for 1989 in addition to waves up to 1991. Burda and Schmidt (1997) employ the waves 1990-1993. Steiner and Wagner (1997), Franz and Steiner (2000), as well as Steiner and Hölzle (2000) estimate wage regressions based on the waves 1990-1995 or 1990-1997, respectively. Burda and Hunt (2001) compare the waves 1990-1999 and Hunt (2001) studies wage growth and job mobility in East Germany based on the waves 1990-1996. She concludes that the observed wage growth patterns provided insufficient incentives for worker mobility, which impeded efficient restructuring and employment recovery.

${ }^{2}$ For further information (on antecedent versions of the IABS) see also Bender, Hilzendegen, Rohwer, and Rudolph (1996) and Bender, Haas, and Klose (2000).
} 
Möller (2005) uses the years 1992-2001 of the IABS to compare raw decile ratios of log wage distributions for some selective labor market groups in 1992 to the respective ratios in 2001. His main findings are that wage inequality has generally been rising between 1992 and 2001 and that the rise in equality has been more pronounced for low-skilled compared to medium-skilled workers and for women compared to men. Starting out at a lower level in 1992, wage inequality in East Germany has largely caught up with the level of inequality in West Germany by 2001. GSOEP survey data employed by Gernandt and Pfeiffer (2006) suggest that the trends toward increasing inequality continued at least until the year 2004 .

In this paper, I also employ the years $1992-2001$ of the IABS. In order to give a comprehensive description for different groups in the labor market I take advantage of the large sample size and consider separate distributions for men working full-time, women working full-time, and women working part-time in East and West Germany in each of the years 1992-2001. For each of these subsamples, I select individuals aged between 25 and 55 years who are not currently in education. Marginal part-time workers (geringfügig Beschäftigte) are not included in the analysis in order to avoid spurious effects through changes in the employment of this group.

Figure 1 depicts the evolution of log nominal daily wages for the different labor market groups. ${ }^{3}$ The deciles changed rather smoothly over the period 1992-2001 so that it makes sense to focus on the two boundary years in the following. Table 1 depicts median wages $L N W 50$ and percentile differences $Q D 8050$ and QD5020 for the different groups in 1992 and 2001. As expected, the wage level is generally higher for men compared to women and for workers in West Germany compared to East Germany in 1992. Until 2001, the gender wage gap narrowed especially in East Germany. The East-West wage gap in the wage level also went down, but persisted to some degree for full-time employees. Figure 2 reveals that convergence in - nominal as well as real-wage levels took place until the year 1996, but then basically stopped: Starting out at 58\%, 34\%, and $17 \%$ in 1992 , the respective nominal differences for men, full-time working women, and part-time working women all shrunk by 7 to 10 real log percentage points (pp). However, only little variation is observed from 1996 on. Nominal differences of 38-40\% and 18-20\% remain for full-time working men and women, but there is virtually no more difference for part-time working

\footnotetext{
${ }^{3}$ At this point I examine nominal wages in order to facilitate East-West comparisons because it is not clear a priori which price deflator and which base year to choose when comparing East and West Germany in real terms; see the discussion in Franz and Steiner (2000). When comparing East and West German wage levels in figure 2 below I also present alternative price normalizations. All comparisons across time in section 4 are based on real wages, deflated by consumer price indices.
} 
women. ${ }^{4}$

Table 1 further shows that wage dispersion as measured by the percentile differences generally increased for all groups between 1992 and 2001. With the only exception of part-time working women the increase was considerably stronger in East Germany than in West Germany. By the year 2001, the level of wage dispersion in the East even exceeds the level in the West. Moreover, there are remarkable differences across groups. For Men in West Germany, QD8050 increased by about 6 pp and QD5020 by 3 pp, adding up to an increase in the interquintile range $Q D 8020$ of $9 \mathrm{pp}$. The larger part of this increase therefore is due to changes in the upper part of the distribution. ${ }^{5}$ Since the 80th percentile for men in East Germany is censored in 1992, an analogous statement for this group cannot be inferred directly from table 1. Yet the results in section 4 show that wages for men in East Germany also went up disproportionately in the upper part of the distribution. ${ }^{6}$ Having said that, wage inequality among full-time working women increased disproportionately in the lower half of the distribution, and most strikingly so in East Germany: whereas QD8050 and QD5020 went up by 3 and 4 pp in the West, the respective numbers for East Germany are 8 and $17 \mathrm{pp}$, adding up to a remarkable increase of the interquintile range $Q D 8020$ of $25 \mathrm{pp}$.

In what follows, the observed distributions are investigated by means of wage regressions for the years 1992 and 2001 to capture the changes over time. The application of (censored) quantile regressions allows to look at between and within inequality, and it sets the stage for the decomposition analyses in section 4. Considering the years 1992 and 2001 is warranted for the following two reasons. First, both years are similar with respect to their location in the West German business cycle: Whereas the unification boom faded out in 1992, the year 2001 marked the end of the new economy boom. Second, the labor force in East Germany dropped sharply from about 10 to below 7 million in the course of the German unification and most of the immediate downturn took place in 1990 and 1991; see Kommission (1996). Net emigration from East Germany was highest between 1989 and 1991; see Hunt (2006). 1992 was the first year with positive GDP growth in East Germany after the unification shock (Burda and Hunt, 2001) and thus is the first year not heavily exposed to distortions resulting from the unification.

\footnotetext{
${ }^{4}$ This effect has already been extensively discussed in the literature; see, e.g., Burda and Schmidt (1997) and Burda and Hunt (2001).

${ }^{5}$ This finding is similar to the trends observed by Fitzenberger (1999) for the period 1975-1990.

${ }^{6}$ The conclusion is also corroborated by Möller's (2005) result for the core group of medium-skilled men.
} 


\section{Wage Regressions}

Let $Y_{s, i} \equiv \ln W_{s, i}$ denote $\log$ wages for individuals $i$, drawn from a distribution $F_{s}\left(Y_{s}\right)$ in an adequately defined labor market segment $s$. Given the focus of this paper one might think of segments as regions (East and West Germany) or different points in time (years). Since the wage data at use are censored from above at the social security taxation threshold $c_{s}$, one observes only $\tilde{Y}_{s, i}=\min \left\{Y_{s, i}, c_{s}\right\}$. One thus might apply Tobit regression (after Tobin, 1956) to estimate the conditional expected value $E\left(Y_{s} \mid X_{s}\right)$ based on covariates $X_{s}$, assuming normality of the error term $u_{s}$ in

$$
Y_{s}=E\left(Y_{s} \mid X_{s}\right)+u_{s}=X_{s} \beta_{s}+u_{s}
$$

A more informative approach is to employ quantile regressions, which do not only capture the expected value, but the entire distribution. As introduced by Koenker and Bassett (1978) and generalized by Powell (1984, 1986), conditional quantiles

$$
Q_{\theta}\left(Y_{s} \mid X_{s}\right)=X_{s} \beta_{s}(\theta)
$$

in the case of censoring from above can be estimated for a given quantile $\theta \in(0,1)$ by minimizing over $\beta_{s}$ the objective function

$$
N_{s}^{-1} \sum_{i=1}^{N_{s}} \rho_{\theta}\left(\tilde{Y}_{s, i}-\min \left\{X_{s, i} \beta_{s}, c_{s}\right\}\right)
$$

where the residuals $u_{s, i}$ are weighted in an asymmetric way by the check function

$$
\rho_{\theta}\left(u_{s, i}\right)= \begin{cases}\theta u_{s, i} & \text { for } \quad u_{s, i} \geq 0 \\ (\theta-1) u_{s, i} & \text { for } \quad u_{s, i}<0\end{cases}
$$

There are different algorithms to solve this non-convex optimization problem in the literature; see, e.g., Buchinsky (1994), Fitzenberger (1997a, 1997b), or Koenker and Park (1996). In the following applications, I apply the Buchinsky algorithm as well as the Fitzenberger algorithm for different starting values and choose the respective best estimator in terms of the objective function (3). Heteroscedasticity consistent standard errors are obtained by means of design matrix bootstraps. Here, it asymptotically suffices to draw on observations for which predicted values are not censored; see Bilias, Chen, and Ying (2000).

Quantile regressions are particularly suited for the purpose of this paper because they do not only reveal differences between, say, different skill or age groups, but also allow these differences to differ across the wage distribution. 


\subsection{Coefficients Across the Distribution}

The estimated log wage equations include a set of formal skill dummies (low-skilled $d_{l}$ : workers without vocational training and without university degree, medium-skilled (base category): those with vocational training and no university degree, and high-skilled $d_{h}$ : employees with university or technical college degree $)^{7}$, (normalized) age, and age squared (agesq). In order to allow for different age-earnings profiles across skill groups I include interaction terms of skill and age as well as skill and agesq, yielding the following specification which is estimated separately for all segments $s$ :

$$
\begin{aligned}
Y_{s i}= & \beta_{1 s}+d_{l, s i} \beta_{2 s}+d_{h, s i} \beta_{3 s}+\operatorname{age}_{s i} \beta_{4 s}+\operatorname{agesq}_{s i} \beta_{5 s} \\
& +d_{l, s i} \text { age }_{s i} \beta_{6 s}+d_{l, s i} \text { agesq }_{s i} \beta_{7 s}+d_{h, s i} \operatorname{age}_{s i} \beta_{8 s}+d_{h, s i} \text { agesq }_{s i} \beta_{9 s}+u_{s i} .
\end{aligned}
$$

All regressions further include a set of industry dummies (16 industries as provided with the IABS 1975-2001) and a dummy for individuals working in Berlin. Observations are weighted by the length of the respective employment spells. Summary statistics of the covariates are displayed in tables 2 and 3.

Figures 3 to 8 show coefficient estimates for censored quantile regressions (CQR) at different deciles of the distributions as well as the corresponding Tobit coefficients. The results are grouped by labor market groups (full-time working men, women working full-time, and women working part-time) and years (1992 and 2001), and each of the figures shows coefficients for West (left panel) and East Germany (middle panel) as well as differences between the two parts of the country (right panel).

In general, the estimated effects are significantly different from zero. Merely some agexskill interactions in East Germany prove insignificant in some parts of the distributions. Moreover, CQR coefficients generally vary significantly across the distribution and differ from the more restrictive Tobit estimates, with the only exception of part-time working women, for whom the confidence bands are relatively wide. The censoring problem is most severe for older high-skilled employees. The interaction terms of age and high skill thus are somewhat sensitive. For example, the median coefficient of age $\times$ high skill for full-time working men in West Germany 2001 is extraordinarily low, whereas the median effect of agesq $\times$ high skill jumps up. At the $60 \%$ quantile, things are reversed. This effect might affect the shape of single age-earnings profiles (see this section below), but its impact on

\footnotetext{
${ }^{7}$ In order to deal with measurement error in the education variable when defining skill groups, I correct the skill information such that formal degrees an individual has once obtained are not lost later on; see also Fitzenberger (1999).
} 
predictions (as used for the decomposition analyses in the next section) can be expected to be small.

Due to the inclusion of the interaction effects, the interpretation of some of the coefficients is not apparent, and I resort to looking at age-earnings profiles in the next subsection. Nevertheless, there are some notable differences of coefficients across quantiles. For example, the effect of age is found to become steeper and more concave at higher quantiles for full-timers. The (negative) base effect of low skill tends to be smallest at low quantiles, and so does the (positive) base effect of high skill. These results are well in line with the predictions of human capital theory; see Becker (1993) and Card (1999).

Looking at West-East differences in the coefficients for the year year 1992, differences in the base effects of skill turn out to be are relatively small. The base trajectory of age is steeper and slightly more concave for men in West Germany, but the picture is reversed for full-time working women, most strikingly in the lower half of the distribution. Differences in the returns to skill among part-time working women are relatively large in the lower half of the distribution. In the year 2001, the differences in the age effects are basically the same as in 1992, but now low-skilled men are particularly worse off in East Germany in the lower half of the distribution. On the other hand, the base return to high skill in East Germany has increased disproportionately at the upper end of the distribution so that one finds a negative difference there.

Changes of the coefficients between 1992 and 2001 can be inferred from figures 9 to 14, which rearrange the estimation results in the left two panels and show the changes between 1992 and 2001 explicitly in the right panel. In West Germany, the base wage has increased, and for full-timers this effect was stronger at higher quantiles. Base skill differentials for both men and women (except for high-skilled part-timers at the top of the distribution) have increased, hinting at an increasing inequality between skill groups. The base returns to age only changed little, though. The changes in East Germany are qualitatively comparable to those in the West. Yet the baseline increased even more distinctly over time, and more pronounced differences across quantiles hint at a higher degree of within dispersion. The negative base wage premium for low skill has grown most strikingly at the lower end of the distribution, whereas the base premium for high-skilled men has grown most at the top of the distribution. 


\subsection{Age-Earnings Profiles}

Figures 15 to 18 present age-earnings profiles used to judge differences in the remunerations of formal skill and age. The two panels display results for West and East Germany, respectively. In most cases, the profiles have the familiar concave form. However, some profiles for high-skilled employees, for whom the censoring problem is most severe, should be interpreted with caution; compare the discussion above.

Figure 15 displays results of the median regressions for different skill groups. Trajectories are generally the steeper the higher the skill level. The only exception is the group of lowskilled women working part-time in East Germany in 2001 which exhibits an exceptionally steep profile. In West Germany, the profiles for women are usually flatter than those for men, but men and women do not differ as much in East Germany.

In East-West comparison, the profiles in the East are flatter and decrease more pronouncedly for older workers in the year 1992. This finding mirrors the low returns to age or experience as human capital components in East Germany in the aftermath of the unification. Yet the difference has lessened by the year 2001, indicating some recovery of returns. Whereas the profiles for West Germany are rather similar between 1992 and 2001, changes occurred in the East, where the profile for high-skilled men became particularly concave - returns recovered most distinctly for high-skilled post-unification cohorts. On the other hand, the profiles of low-skilled women improved for part-timers, but deteriorated for full-timers. Given the position of the low-skilled at the lower end of the unconditional wage distribution, this effect contributes substantially to the asymmetric rise in dispersion among women working full-time in East Germany.

The general picture is also reflected in figures 16 to 18 which display skill-specific profiles at different quantiles $(20 \%, 50 \%$, and $80 \%)$. Standard profiles with steeper trajectories in higher regions of the distribution are primarily observed for the core labor market group of male full-timers with an apprenticeship degree. When looking at (full-time as well as part-time working) women in West Germany in the year 2001, one finds an analogous standard ordering of the profiles for the high-skilled, but a reversed ordering for the lowskilled: Women with low formal qualification gain most from accumulating experience at the lower end of the pay scale. In East Germany, the profiles decrease for older workers across all quantiles. Yet high-skilled men at younger age gained most in the upper part of the distribution and the position of older low-skilled women deteriorated particularly at the lower end. Again, the findings underline the depreciation of human capital and the asymmetric recovery in the aftermath of the unification. 


\section{Decomposing Differences Across Wage Distribu- tions}

The above regression analyses provided detailed insights into the remuneration of observed worker characteristics in different labor market segments and in different parts of the wage distribution. Decomposition analyses are well-suited to complement the regression evidence by answering the question whether differences in observed distributions result from differences in estimated coefficients or from differences in the composition of the workforce. I focus on differences between East and West Germany and on changes of the respective wage structures over time.

A Blinder (1973)-Oaxaca (1973)-type decomposition for the difference between the expected wages in two segments $s$ and $\tilde{s}$ is:

$$
E\left(Y_{s} \mid X_{s}\right)-E\left(Y_{\tilde{s}} \mid X_{\tilde{s}}\right)=\left(X_{s}-X_{\tilde{s}}\right) \beta_{s}+X_{\tilde{s}}\left(\beta_{s}-\beta_{\tilde{s}}\right)
$$

To apply the Blinder-Oaxaca (B-O) decomposition in case of censored data, I evaluate equation (6) at mean values of the characteristics and use the coefficients estimated by means of Tobit regressions. ${ }^{8}$

The first summand on the right hand side of equation (6), traditionally labelled "characteristics effect", captures the part of the difference that is attributable to differences in the covariates across the two segments. The second summand known as "returns" or "coefficients effect" captures the part of the difference that is attributed to differences in the returns to the covariates. When decomposing West-East wage gaps in the next section, I choose the counterfactual $X_{\text {East }} \beta_{\text {West }}$ to answer the question what the expected log wage would have been, had a population with the same distribution of characteristics as East Germany faced returns to characteristics as in the West. ${ }^{9}$ The approach assumes that the West German returns are the relevant benchmark for the distribution in the absence of any "discrimination". In case of the comparison across time in section 4.2 the

\footnotetext{
${ }^{8}$ In contrast to the traditional OLS case, however, the predicted conditional difference does not necessarily coincide with the observed mean difference. "Observed" mean wages in the censoring case have to be estimated by means of Tobit regressions on a constant.

${ }^{9} \mathrm{It}$ is well known that the partition depends on the ordering of the effects and that the decomposition results may not be invariant with respect to the choice of the involved counterfactual $X_{\tilde{s}} \beta_{s}$; see the surveys of Oaxaca and Ransom (1994) and Silber and Weber (1999). Therefore, the choice of a counterfactual should be guided by the question of economic interest.
} 
counterfactual $X_{1992} \beta_{2001}$ hypothesizes what the expected wage would have been in face of returns in the year 2001, had the distribution of characteristics not changed since $1992 .{ }^{10}$ A further method introduced by Juhn, Murphy, and Pierce (1991) and applied in a series of papers by Blau and Kahn $(1992,1994,1997)$ also decomposes the change of a wage gap over time. This approach has got the additional merit that it decomposes also residual effects into a quantity and a price effect. However, it suffers from the shortcoming that it assumes unique coefficients across segments $s$ and $\tilde{s}$. What is more, the decomposition of the residual terms is inapplicable in the case of censored data, in which residuals can only be used for uncensored observations.

The main disadvantage of all techniques discussed so far is that all of them consider only mean effects. In contrast, Machado and Mata (2005) build on quantile regressions to decompose differences across entire distributions. They propose an estimator $F_{s}^{*}\left(Y_{s}\right)$ of the marginal distribution of wages which conforms to the linear conditional model (2) as follows:

1. Draw $M$ numbers $\theta^{1}, \ldots, \theta^{M}$ at random from a uniform distribution $U(0,1)$.

2. For each $\theta^{m}$, estimate the conditional quantile (2), using the sample $\left\{Y_{s, i}, X_{s, i}\right\}_{i=1}^{N_{s}}$. This yields coefficient estimates $\hat{\beta}_{s}\left(\theta^{1}\right), \ldots, \hat{\beta}_{s}\left(\theta^{M}\right)$.

3. Draw $M$ random draws $X_{s}^{1}, \ldots, X_{s}^{M}$ from the sample $\left\{X_{s, i}\right\}_{i=1}^{N_{s}}$.

4. Then, the data set $\left\{Y_{s}^{* m} \equiv X_{s}^{m} \hat{\beta}_{s}\left(\theta^{m}\right)\right\}_{m=1}^{M}$ constitutes a random sample from $F_{s}^{*}\left(Y_{s}\right)$.

An estimator $F_{s}^{*}\left(Y_{s}\left(X_{\tilde{s}}\right)\right)$ of the counterfactual marginal distribution, which relies on the coefficients of segment $s$ but on the characteristics of segment $\tilde{s}$, can be obtained in an analogous way by drawing resamples from $X_{\tilde{s}}$ rather than from $X_{s}$ in the third step.

\footnotetext{
${ }^{10}$ There are alternative methodologies to the standard B-O decompositions in the literature. In light of the present focus on differences in two dimensions, techniques to decompose changes of wage gaps over time in one single exercise — as proposed by Smith and Welch (1989) or Wellington (1993) — would be of particular interest. However, I opt to consider both decompositions separately for two reasons. First, any combination of involved counterfactuals - be it with or without interaction terms between the differences in characteristics and differences in coefficients - bears an even higher degree of arbitrariness; see Le and Miller (2004). Second, and most importantly, each of the two comparisons, the differences between East and West Germany as well as the changes of the wage distributions within the two regions over time, is interesting of its own.
} 
The Machado/Mata (MM) decomposition based on the estimated distributions therefore writes

$$
\begin{aligned}
\hat{F}_{s}\left(Y_{s}\right)-\hat{F}_{\tilde{s}}\left(Y_{\tilde{s}}\right) & =F_{s}^{*}\left(Y_{s}\right)-F_{\tilde{s}}^{*}\left(Y_{\tilde{s}}\right)+\epsilon \\
& =\left[F_{s}^{*}\left(Y_{s}\right)-F_{s}^{*}\left(Y_{s}\left(X_{\tilde{s}}\right)\right)\right]+\left[F_{s}^{*}\left(Y_{s}\left(X_{\tilde{s}}\right)\right)-F_{\tilde{s}}^{*}\left(Y_{\tilde{s}}\right)\right]+\epsilon,
\end{aligned}
$$

where $\hat{F}_{s}(\cdot)$ denotes an estimator of the distribution based on the observed sample. Similar to the B-O decomposition, the term in the first brackets on the right hand side of (7) is a characteristics effect, and the one in the second brackets a returns effect. Provided that the linear specification (2) is appropriate, the residual term $\epsilon$ is negligible for large samples. With respect to the choice of a counterfactual distribution the same caveat as in the B-O case applies.

I employ the MM technique, resorting to quantile measures for the involved distributions in order to gauge the elements of the decompositions. However, a couple of adaptations are undertaken. First, I estimate CQR as explained above. Second, I follow Albrecht, Björklund, and Vroman (2001) to save computation time: Rather than drawing $M$ random numbers for $\theta^{m}$ and then estimating $M$ (censored) quantile regressions, I estimate one regression for each single percentile and then draw $M=1000$ random draws from the distributions of the covariates for each $\hat{\beta}_{s}(\cdot)$. Third, and finally, predictions above the SSTT are censored to this value in order to replicate the censoring of the wage data. As a consequence, all comparisons of the simulated distributions $F_{s}^{*}(\cdot)$ consider only the respective uncensored parts.

There are also alternative approaches in the literature for decomposing differences across entire distributions. The decomposition introduced by Juhn, Murphy, and Pierce (JMP, 1993), which is also used by Blau and Kahn (1996) for cross-country comparisons and by Steiner and Wagner $(1997,1998)$ and Gernandt and Pfeiffer (2006) for German data, employs the distribution of residuals resulting from wage regressions to rank observations. This approach gives a structural interpretation to the regression residual. Yet it faces a couple of shortcomings. First, its focus on the distribution of residuals renders the approach as inapplicable in the case of censored data as the related (1991) approach. Second, even without censoring of the data, the JMP (1993) decomposition is valid only in the case of homoscedasticity, which is usually rejected for empirical wage regressions. Third, and most importantly, it is more restrictive than the MM technique because it assumes a single linear model to hold for the entire wage distribution, whereas the latter approach based on quantile regressions allows for flexibility across the distribution. 
Autor, Katz, and Kearney (2005a) also build on the MM approach, while DiNardo, Fortin, and Lemieux (1996) exploit kernel density estimations to decompose differences in a nonparametric setting. Compared to this approach, the semiparametric MM framework is restrictive by nature. Yet by quantifying differences in the coefficients it sheds light on that part of a difference which would be left unexplained in the nonparametric framework.

\subsection{Differences between East and West Germany}

Table 4 reports observed and predicted West-East differences in log wages across quantiles for the years 1992 and 2001. ${ }^{11}$ Observed and predicted quantiles of the unconditional wage distributions show a close resemblance, therefore suggesting that the estimation and specification error is of minor importance. The predicted gaps thus broaden the snapshot discussion of section 2. Decile differences which cannot be interpreted due to the censoring problem are marked by a dot. The Tobit results reported in the last column are usually close to the values at the median.

For the group of full-time working men the gap varies between $55 \%$ at the first decile and $61 \%$ at the eighth decile in 1992 . The observation that the gap at the upper end of the distribution exceeds the gap at the lower end by $6 \mathrm{pp}$ indicates a higher wage dispersion in the West as compared to the East. In 2001 the East-West differential varies less between quantiles (38\% at the first decile and $40 \%$ at the eighth): Wage dispersion in East Germany has caught up to a large degree. Except for the difference in the level, the picture for women working full-time in 1992 is very similar to that for males in the upper two thirds of the distribution: The gaps at the third and at the eighth decile differ by 4 pp. However, the gap of $22 \%$ at the first decile falls below the gap at the third decile by remarkable $14 \mathrm{pp}$ - at the very low end of the distribution the West-East gap is less severe. This finding still holds for the year 2001, but now the differential at the third decile also exceeds the differential at the eighth by 9 pp: The upper half of this group's distribution participated most strikingly in the closing of the West-East wage gap. Women working part-time in East Germany in 1992 were relatively well off at the low and at the high end of the distribution, and the West-East differential was highest around the median. The differential for this group had basically vanished by 2001, though. At the first decile wages were even slightly higher in the East.

When decomposing West-East wage differentials in order to judge whether the differentials stem from different decompositions of the work force or whether employees' characteristics

\footnotetext{
${ }^{11}$ The analysis in this section is based on nominal numbers; see the discussion in section 2 .
} 
are remunerated differently in East and West Germany, one generally finds relatively small impacts of the characteristics. The better parts of the differentials are in most cases captured by differences in the coefficients.

For full-time working men the characteristics effect is largely negligible in both years 1992 and 2001. If anything, different characteristics explain 2 pp of the West-East differential in the upper part of the distribution in 2001. In the group of women working full-time in 1992, the characteristics effect ranges between $-9 \mathrm{pp}$ at the first decile and $-6 \mathrm{pp}$ at the eighth. It therefore is in favor of higher earnings in East Germany and most pronounced in the lower half of the distribution. In relative terms, women selecting into full-time jobs in East Germany had more preferable characteristics in 1992. This tendency still holds for 2001, but to a lesser degree and mainly in the upper half of the distribution. In the lower part of the distribution the relative deterioration of characteristics contributed substantially to the worsened position in the pay scale. A similar reasoning also applies for women working part-time in 1992. However, there are only little offsetting characteristics and coefficients effects in the year 2001, by which convergence of wages has been achieved for this group.

The conclusion that differences in employees' characteristics only play a minor role in explaining East-West wage differentials is supported by the summary statistics of the covariates in tables 2 and 3. By and large, differences are very small. In both years 1992 and 2001 and for all labor market groups, the level of formal education in East Germany is higher than in the West. Only the proportion of male employees with a university degree is higher in West Germany in 2001.

The latter finding is in line with the results of the B-O decompositions in Burda and Schmidt (1997) and the JMP decompositions in Steiner and Wagner (1997), both of which use GSOEP data for the early 1990s and report a minor importance of differences in the characteristics of the work forces. Görzig, Gornig, and Werwatz (2004), using a decomposition based on establishment-level data, compare wages in East and West Germany for the years 1994 and 1998. They stress the importance of differences in establishment types and conclude that the catching-up in the East was in part offset by an increasing share of low-wage-type establishments in East Germany. The analysis of East-West migrants in Kirbach and Smolny (2004) also concludes that only a small part of observed East-West wage gaps can be attributed to observed socioeconomic characteristics of the workers. 


\subsection{Changes in the Wage Structure Over Time}

In order to analyze changes in the wage structure over time, I use real wages (normalized by consumer prices of 1992, differentiated by regions). In a setup analogous to that of table 4 in the previous section, the panels in table 5 display the observed and predicted log wage changes between 1992 and 2001. Differences of the numbers across quantiles give account of the evolution of wage inequality.

Among the group of men working full-time in West Germany, inequality as measured by percentile differences $Q D 8020$ has increased by $9 \mathrm{pp}$ and this increase was slightly more pronounced in the upper half of the distribution. The eighth decile gained $5 \%$ while the second decile lost by $4 \%$. Due to the censoring problem, changes at the very high end of the distribution cannot be assessed, but wages at the very low end exhibited a remarkable real loss of almost 8\%. The (predicted) interquintile range QD8020 of $14 \mathrm{pp}$ for men in East Germany shows that wage dispersion went up even more remarkably. Moreover, most of this increase $(10 \mathrm{pp})$ took place in the upper half of the distribution. Yet even at the lower end real wage growth was positive for this group.

Real wages of women working full-time in West Germany did hardly change in the lower third of the distribution. Only the first decile exhibited a decline of $2 \%$. Negative real wage growth of up to $-4 \%$ is found in the lower third of the distribution for this group in East Germany. The gender wage gap in East Germany thus did not close, but rather widen in this part of the distribution. Wage growth further differed substantially at higher quantiles: Whereas Western wages increased by up to $8 \%$, wages in the East went up by remarkable $23 \%$ at the eighth decile. The corresponding interquintile range QD8020 of 25 pp shows that the increase in inequality was most striking among this group.

The group of part-time working women in West Germany experienced real wage growth between 5 and 11\%, with highest increases at the extreme deciles. In East Germany, the range of differences across quantiles is $9 \mathrm{pp}$. However, the biggest increase is observed in the middle part of the distribution and - well in line with the observed closing of the East-West gap for this group - the level of changes exceeds that in the West by about 10 pp.

The decomposition of the wage changes reveals characteristics effects in the range between 1 pp (in favor of higher earnings in 2001) at the first decile and 5 pp at the eighth decile for all three labor market groups working in West Germany. With shares of about one half for women and virtually full coverage for men, changes in the characteristics therefore capture the better part of the respective wage increases in the upper halves of the distributions. 
The finding likely reflects some skill upgrading in the prime-age work force. In fact, reconsidering the summary statistics of the covariates in tables 2 and 3, one finds that skill upgrading took place in both East and West Germany between 1992 and 2001. As the proportion of low-skilled workers decreased in all labor market groups, the proportion of high-skilled went up. This increase was more pronounced in West Germany than in the East. With respect to changes in the industry structure of the work force, employment in public and social security system services (sector 16) decreased most remarkably in East Germany.

Restructuring and skill upgrading yet played only a minor role in explaining the striking wage increase (especially in the upper half of the distribution) for men working in East Germany: The characteristics effect does not exceed 2 pp. A similar result holds for the majority of women working full-time in East Germany, but for this group the characteristics effect goes down up to $-7 \mathrm{pp}$ in the lower middle of the distribution. The characteristics in that part of the distribution working toward real wage cuts, the increasing inequality was driven by a more advantageous development of characteristics at the upper end. Finally, the contribution of changes in the characteristics is largely negligible across the entire distribution of wage changes for women working part-time in East Germany.

A bottom line of this exercise is that the diverse patterns of changing wage levels and increasing inequality are due to changes in the composition of the respective work forces and changing remunerations of relevant characteristics. This result differs from that of related studies in the literature ${ }^{12}$, all of which use the more restrictive B-O or JMP decompositions for different periods of time and find basically no composition effects among prime-age employees.

\section{Conclusions}

The German wage structure has been rather compressed in international comparison and "unbearabl[y] stable" (Prasad, 2000) between the mid 1970s and the mid-1990s. Newly available register data from the IAB employment sample 1975-2001 now allow

\footnotetext{
${ }^{12}$ Steiner and Wagner (1998) analyze the evolution of wage inequality among West German males by means of JMP decompositions applied to GSOEP and IABS data for the years 1984-1990. Note that their analysis for the IABS bears some problems because it only considers uncensored wages. Burda and Hunt (2001) apply B-O decompositions to the GSOEP East 1990-1999. Gernandt and Pfeiffer (2006) also use GSOEP data for 1984-2004 and apply JMP decompositions.
} 
to reinvestigate the empirical evidence for more recent years. This paper studies the evolution of wage levels and wage inequality within and between different labor market groups for the years 1992-2001. I find that wage inequality has in fact been rising in many dimensions throughout this period.

A comparison of mean wage differences reveals that convergence in wage levels between West and East Germany took place up to the year 1996, but nominal differences of about $40 \%$ for men and $20 \%$ for full-time working women persisted until 2001 . No more difference is observed in the wages of part-time working women.

The inspection of year-specific wage distributions unveils rising wage dispersion. As measured by interquintile ranges $Q D 8020$, dispersion was generally lower in East Germany than in West Germany in the year 1992, but it caught up until 2001: Whereas QD8020 increased by 8 to 9 log percentage points (pp) for men and full-time working women in West Germany, the corresponding numbers are 14 to $25 \mathrm{pp}$ in the East. Moreover, the larger part of the increase in dispersion among women happened in the lower parts of the respective distributions, but dispersion among men increased disproportionately in the upper parts.

The estimation of censored quantile wage regressions provides insights into the determinants of the observed differences and changes. The bottom line of the regression results meets a-priori expectations. Age-earnings profiles not only are the steeper the higher the skill level, but they are also relatively flat in East Germany in 1992. The unification shock clearly led to a depreciation of human capital in the East. However, this effect wears out with the aging of post-unification labor market cohorts, and differences in the profiles between East and West Germany have lessened by the year 2001. The quantile regression approach further reveals significant differences in the effects across the wage distribution. The result that low-skilled women working full-time in East Germany are left particularly worse-off at the lower end of the distribution substantiates the high and asymmetric increase in dispersion for this group.

Drawing on the flexible quantile regression approach, the decomposition technique introduced by Machado and Mata (2005) is well-suited to depict heterogeneous characteristics and coefficients effects across the respective wage distributions. In East-West comparison, differences in the composition of the work force turn out largely negligible for men. However, characteristics of full-time working women are mostly in favor of higher wages in the East. Yet this effect ceased to apply at the lower end of the distribution by the year 2001. 
With respect to the evolution of wages over time, characteristics effects capture major parts of the respective wage increases in the upper halves of the wage distributions for West Germany. This finding reflects a skill upgrading in the work force. Restructuring and skill upgrading yet played only a minor role in explaining the wage increases in East Germany. For women in the lower parts of the Eastern distribution the characteristics effect even worked toward real wage cuts, substantiating again the particular increase in wage dispersion among this group.

The finding of rising wage inequality is broadly in line with the evidence in Möller (2005), who compares decile ratios for selective labor market groups and also stresses the importance to distinguish between men and women when assessing asymmetries in the evolution of wage inequality. Gernandt and Pfeiffer (2006), also reporting increasing wage inequality, do not distinguish between sexes and therefore do not give account of the striking asymmetries between the groups in East Germany. As a consequence, their JMP decompositions do not detect this effect, either.

All of the results discussed in this paper are descriptive by nature. Unfortunately, the IABS provides only relatively few covariates, such that it is impossible to venture upon instrumental variable estimation or a control function approach in order to account for a possible endogeneity of educational attainment or differences in the selection into the labor market. The analysis focusses on core labor market groups and leaves aside marginal parttime workers (geringfügig Beschäftigte), among others. This is important to note because it renders the finding of increasing inequality even more meaningful.

An analogous argument applies with respect to migration, which is not modeled explicitly. East-West migration in the aftermath of the unification had already come down to stable numbers by the year 1992 and the evidence for the existence of a brain drain is mixed; see Arntz (2006), Büchel, Frick, and Witte (2002), and Hunt (2006). However, if emigration from East Germany during the observation period is skill- or age-biased, i. e., if migrants are in fact either better educated workers or low-skilled who have been laid-off (Hunt, 2006), the observation that wage inequality increases faster in East Germany is even more remarkable.

Finally, it is not the aim of this paper to speculate about the economic causes and consequences of the unveiled trends. In face of alternative explanatory hypotheses - such as accelerating non-neutral technical change, increasingly heterogenous work environments, more flexible labor market institutions, or a decline in union power-estimates of structural models may be expected to complement the descriptive evidence in future research. 


\section{References}

Acemoglu, D. (2002): "Technical Change, Inequality, and the Labor Market," Journal of Economic Literature, 40, 7-72.

Albrecht, J., A. Buörklund, and S. Vroman (2001): "Is There a Glass Ceiling in Sweden?," Journal of Labor Economics, 21(1), 145-177.

Arntz, M. (2006): "What attracts human capital? Understanding the skill composition of internal migration flows in Germany," unpublished manuscript, ZEW Mannheim.

Autor, D. H., L. F. Katz, and M. S. Kearney (2005a): "Rising Wage Inequality: The Role of Composition and Prices," Working Paper 11628, NBER.

(2005b): "Trends in U.S. Wage Inequality: Re-Assessing the Revisionists," Working Paper 11627, NBER.

Büchel, F., J. R. Frick, and J. C. Witte (2002): "Regionale und berufliche Mobilität von Hochqualifizierten - Ein Vergleich Deutschland-USA," in Arbeitsmärkte für Hochqualifizierte, ed. by L. Bellmann, and J. Velling, Beiträge zur Arbeitsmarktund Berufsforschung 256, pp. 207-243. Institut für Arbeitsmarkt- und Berufsforschung, Nürnberg.

Becker, G. S. (1993): Human Capital: A Theoretical and Empirical Analysis with Special Reference to Education. The University of Chicago Press, Chicago, London, 3rd edn.

Bender, S., A. HaAs, and C. Klose (2000): "The IAB Employment Subsample 1975-1995," Schmollers Jahrbuch, 120(4), 649-662.

Bender, S., J. Hilzendegen, G. Rohwer, and H. Rudolph (1996): Die IABBeschäftigtenstichprobe 1975-1990, Beiträge zur Arbeitsmarkt- und Berufsforschung 197. Institut für Arbeitsmarkt- und Berufsforschung, Nürnberg.

Bilias, Y., S. Chen, and Z. Ying (2000): "Simple Resampling Methods for Censored Regression Quantiles," Journal of Econometrics, 99, 373-386.

Bird, E. J., J. Schwarze, And G. Wagner (1994): "Wage Effects of the Move Toward Free Markets in East Germany," Industrial and Labor Relations Review, 47(3), 390-400. 
Blau, F. D., And L. M. KAhn (1992): "The Gender Earning Gap: Learning from International Comparisons," American Economic Review, 82(2, Papers and Proceedings), $533-538$.

(1994): "Rising Wage Inequality and the U.S. Gender Gap," American Economic Review, 84(2, Papers and Proceedings), 23-28.

(1996): "International Differences in Male Wage Inequality: Institutions versus Market Forces," Journal of Political Economy, 104(4), 791-837.

(1997): "Swimming Upstream: Trends in the Gender Wage Differential in the 1980s," Journal of Labor Economics, 15(1), 1-42.

Blinder, A. S. (1973): "Wage Discrimination: Reduced Form and Structural Estimates," Journal of Human Resources, 8(4), 436-455.

Buchinsky, M. (1994): "Changes in the U.S. Wage Structure 1963-1987: Application of Quantile Regression," Econometrica, 62(2), 405-458.

Burda, M. C., And J. Hunt (2001): "From Reunification to Economic Integration: Productivity and the Labor Market in Eastern Germany," Brookings Papers on Economic Activity, 2, 1-92, including discussions.

Burda, M. C., And C. M. Schmidt (1997): "Getting behind the East-West Wage Differential: Theory and Evidence," in Wandeln oder Weichen - Herausforderungen der wirtschaftlichen Integration für Deutschland, ed. by R. Pohl, and H. Schneider, pp. 170-201. IWH Halle, Sonderheft Wirtschaft im Wandel.

CARD, D. (1999): "The Causal Effect of Education on Earnings," in Handbook of Labor Economics, ed. by O. Ashenfelter, and D. Card, vol. 3, chap. 30, pp. 1801-1863. Elsevier Science.

DiNardo, J., N. M. Fortin, and T. Lemieux (1996): "Labor Market Institutions and the Distribution of Wages, 1973-1992: A Semiparametric Approach," Econometrica, 64(5), 1001-1044.

Fitzenberger, B. (1997a): "A Guide to Censored Quantile Regressions," in Handbook of Statistics, ed. by G. S. Maddala, and C. R. Rao, vol. 15: Robust Inference, pp. 405-437. Elsevier Science. 
(1997b): "Computational aspects of censored quantile regression," in $L_{1}$ Statistical Procedures and Related Topics, ed. by Y. Dodge, vol. 31 of IMS Lecture Notes - Monograph Series, pp. 171-186. Institute of Mathematical Statistics, Hayward, CA.

(1999): Wages and Employment Across Skill Groups: An Analysis for West Germany. Physica, Heidelberg.

Fitzenberger, B., And K. Kohn (2005): "Skill Wage Premia, Employment, and Cohort Effects in a Model of German Labor Demand," unpublished manuscript, GoetheUniversity Frankfurt.

Franz, W., And V. Steiner (2000): "Wages in the East German Transition Process: Facts and Explanations," German Economic Review, 1(3), 241-269.

Gernandt, J., and F. Pfeiffer (2006): "Rising Wage Inequality in Germany," Discussion Paper 06-19, ZEW Mannheim.

Görzig, B., M. Gornig, and A. Werwatz (2004): "East Germanys Wage Gap: A non-parametric decomposition based on establishment characteristics," Discussion Paper 451, DIW Berlin.

Hamann, S., G. Krug, M. Köhler, W. Ludwig-Mayerhofer, and A. Hacket (2004): "Die IAB-Regionalstichprobe 1975-2001: IABS-R01," ZA-Information, 55, 3459.

Hunt, J. (2001): "Post-Unification Wage Growth in East Germany," Review of Economics and Statistics, 83(1), 190-195.

(2006): "Staunching Emigration from East Germany: Age and the Determinants of Migration," Journal of the European Economic Association, p. forthcoming.

Juhn, C., K. M. Murphy, And B. Pierce (1991): "Accounting for the slowdone in black-white wage convergence," in Workers and their Wages, ed. by M. H. Kosters, pp. 107-143. AEI Press.

(1993): "Wage Inequality and the Rise in Returns to Skill," Journal of Political Economy, 101(3), 410-442.

Katz, L. F., And D. H. Autor (1999): "Changes in the Wage Structure and Earnings Inequality," in Handbook of Labor Economics, ed. by O. Ashenfelter, and D. Card, vol. 3, chap. 26, pp. 1463-1555. Elsevier Science. 
Kirbach, M., And W. Smolny (2004): "Wage differentials between East and West Germany - Is it related to the location or to the people?," unpublished manuscript, University of Ulm and ZEW, Mannheim.

Koenker, R., And G. Bassett, JR. (1978): "Regression Quantiles," Econometrica, 46(1), 33-50.

Koenker, R., AND B. J. PARK (1996): "An interior point algorithm for nonlinear quantile regression," Journal of Econometrics, 71, 265-283.

Kommission FÜr ZukUnftsfragen Der FreistaAten BayERN UND SACHSEN (1996): "Erwerbstätigkeit und Arbeitslosigkeit in Deutschland - Entwicklung, Ursachen und Maßnahmen," http://www.bayern.de/imperia/md/content/stk/allgemein/bericht1.pdf.

Krueger, A., And J.-S. Pischke (1995): "A Comparative Analysis of East and West German Labor Markets: Before and After Unification," in Differences and Changes in Wage Structures, ed. by R. B. Freeman, and L. F. Katz, pp. 405-445. University of Chicago Press, Chicago, London.

Le, A. T., And P. W. Miller (2004): "Inter-Temporal Decompositions of Labour Market and Social Outcomes," Australian Economic Papers, 43(1), 10-20.

Machado, J. A. F., And J. Mata (2005): "Counterfactual Decomposition of Changes in Wage Distributions using Quantile Regression," Journal of Applied Econometrics, 20(4), 445-465.

MöLler, J. (2005): "Die Entwicklung der Lohnspreizung in West- und Ostdeutschland," in Institutionen, Löhne und Beschäftigung, ed. by L. Bellmann, O. Hübler, W. Meyer, and G. Stephan, Beiträge zur Arbeitsmarkt- und Berufsforschung 294, pp. 47-63. Institut für Arbeitsmarkt- und Berufsforschung, Nürnberg.

OAXACA, R. (1973): "Male-female wage differentials in urban labour markets," International Economic Review, 14, 693-709.

OAxacA, R. L., And M. R. Ransom (1994): "On discrimination and the decomposition of wage differentials," Journal of Econometrics, 61, 5-21.

Powell, J. L. (1984): "Least absolute deviations for the censored regression model," Journal of Econometrics, 25, 303-325.

(1986): "Censored regression quantiles," Journal of Econometrics, 32, 143-155. 
Prasad, E. S. (2000): "The Unbearable Stability of the German Wage Structure: Evidence and Interpretation," Working Paper 00/22, IMF.

Riphahn, R. (2003): "Bruttoeinkommensverteilung in Deutschland 1984-1999 und Ungleichheit unter ausländischen Erwerbstätigen," in Wechselwirkungen zwischen Arbeitsmarkt und sozialer Sicherung II, ed. by W. Schmähl, vol. 294 of Schriften des Vereins für Socialpolitik, pp. 135-174. Duncker \& Humblot, Berlin.

Schwarze, J. (1993): "Qualifikation, Überqualifikation und Phasen des Transformationsprozesses - Die Entwicklung der Lohnstruktur in den neuen Bundesländern," Jahrbücher für Nationalökonomie und Statistik, 211, 90-107.

Schwarze, J., And G. WaGner (1992): "Lohnstruktur und Lohnniveau in den neuen Bundesländern," Wirtschaftsdienst, pp. 202-206, Heft IV.

Silber, J., AND M. WeBer (1999): "Labour market discrimination: are there significant differences between the various decomposition procedures?," Applied Economics, 31, $359-356$.

Smith, J. P., And F. R. Welch (1989): "Black Economic Progress After Myrdal," Journal of Economic Literature, 27, 519-564.

Steiner, V., And T. Hölzle (2000): "The Development of Wages in Germany in the 1990s - Description and Explanations," in The Personal Distribution of Income in an International Perspective, ed. by R. Hauser, and I. Becker, pp. 7-30. Springer.

Steiner, V., And K. Wagner (1997): "East-West Wage Convergence - How Far Have We Got?," Discussion Paper 97-25, ZEW Mannheim.

(1998): "Has Earnings Inequality in Germany Changed in the 1980's?," Zeitschrift für Wirtschafts- und Sozialwissenschaften, 118(1), 29-59.

Tobin, J. (1956): "Estimation of Relationships for Limited Dependent Variables," Econometrica, 26, 24-36.

Wellington, A. J. (1993): "Changes in the Male/Female Wage Gap, 1976-85," Journal of Human Resources, 28(2), 383-411. 
Figure 1: Nominal Wage Distributions, 1992-2001
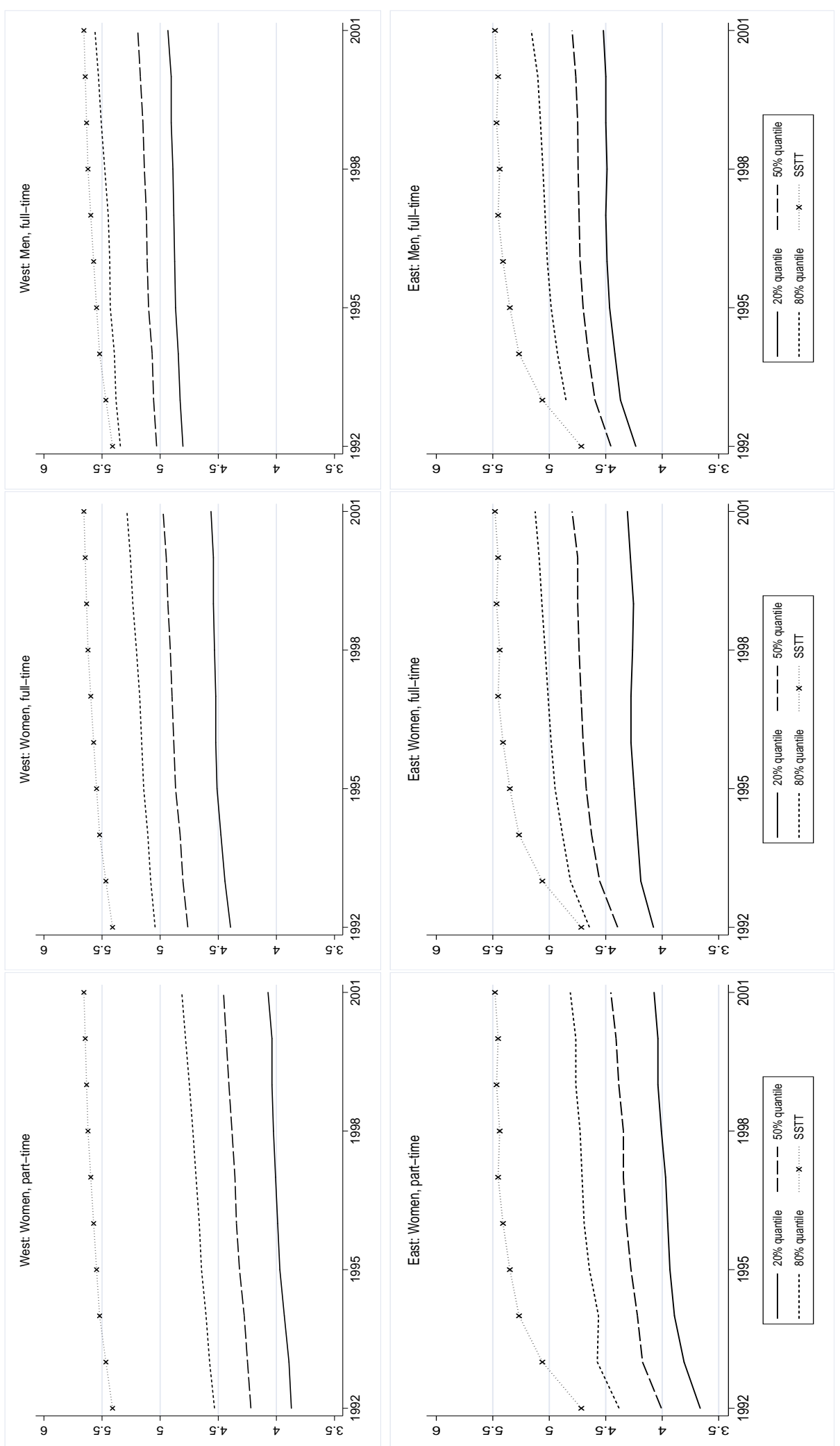

Raw quantiles of log nominal daily wage distributions. SSTT: social security taxation threshold. Data source: IABS 1975-2001. 


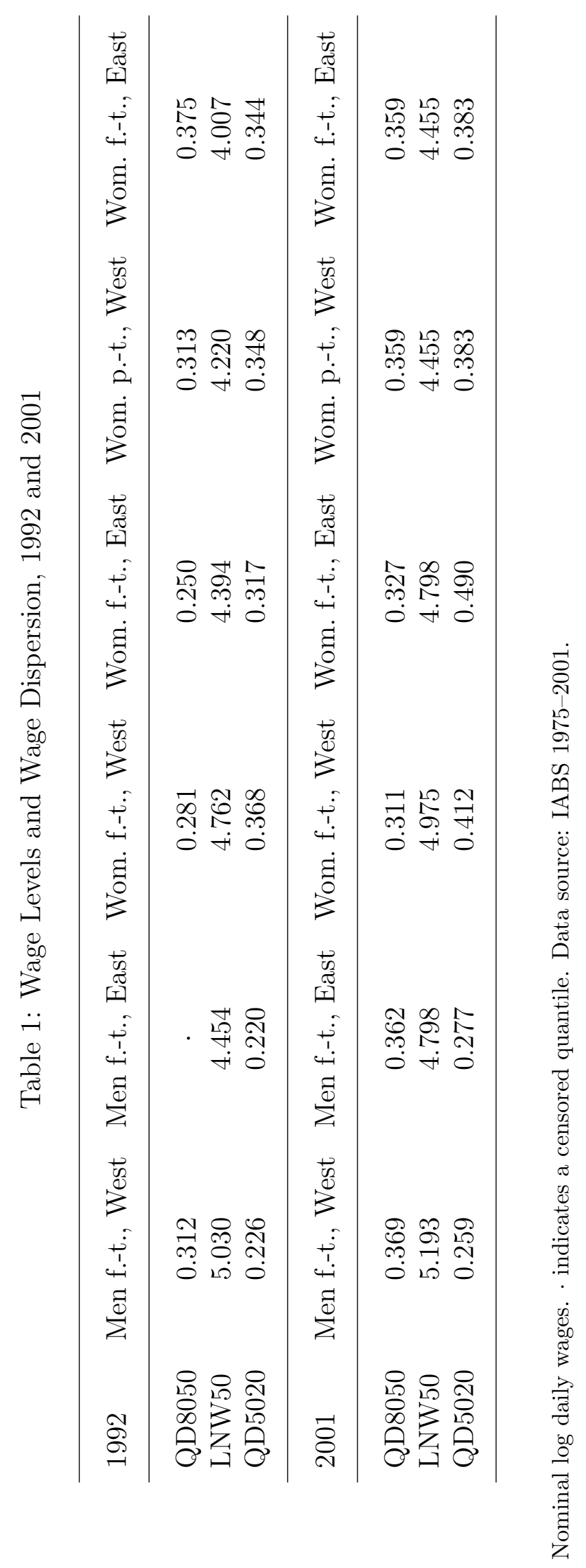


Figure 2: West-East Wage Gaps, 1992-2001
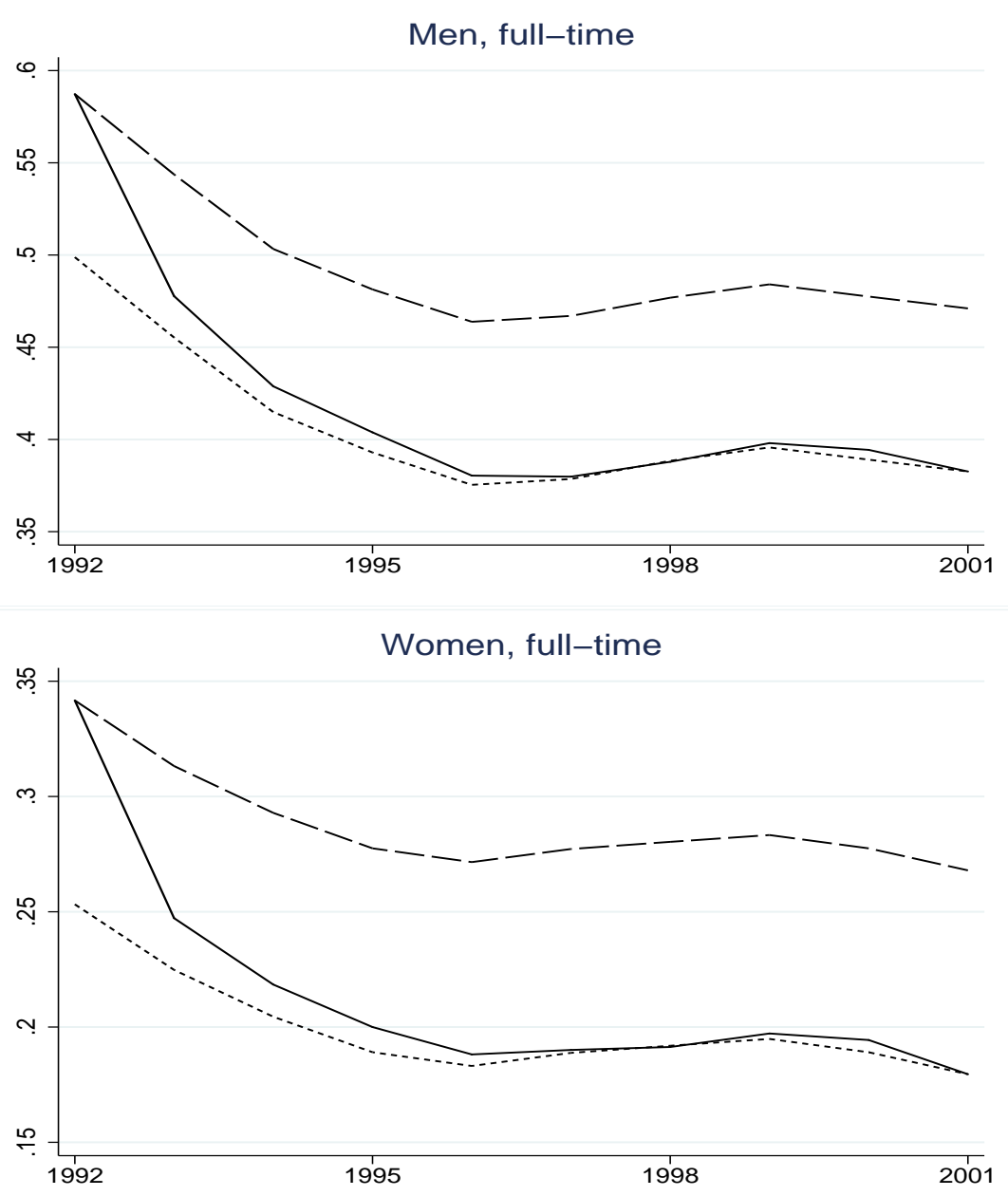

Women, part-time

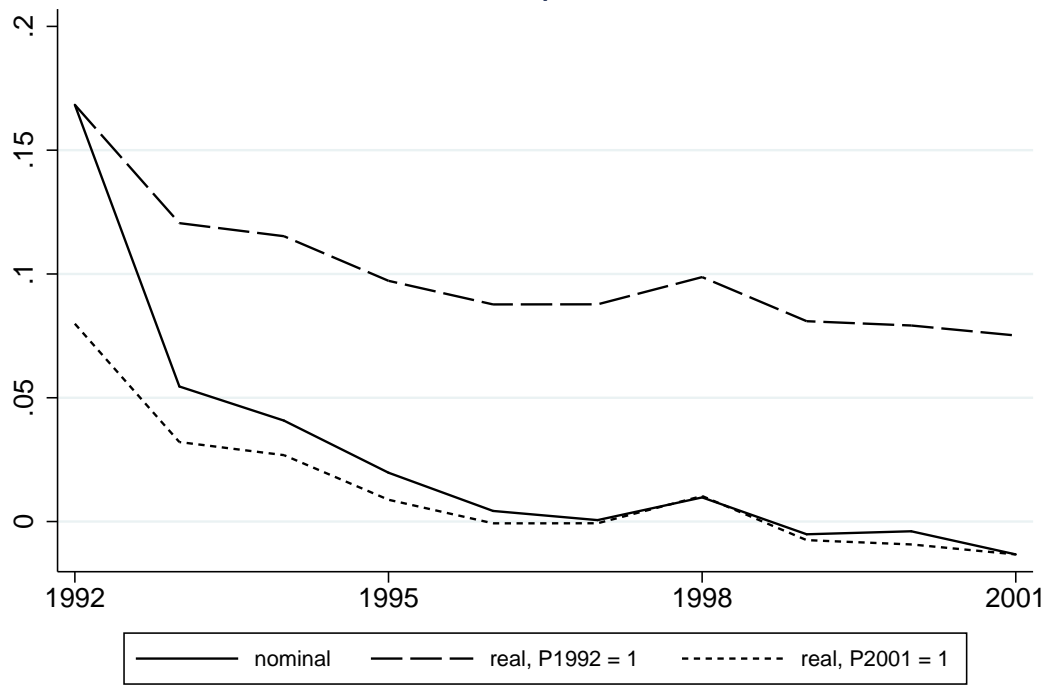

Differences of mean log wages, estimated by Tobit regressions on a constant. Data source: IABS 1975-2001. 


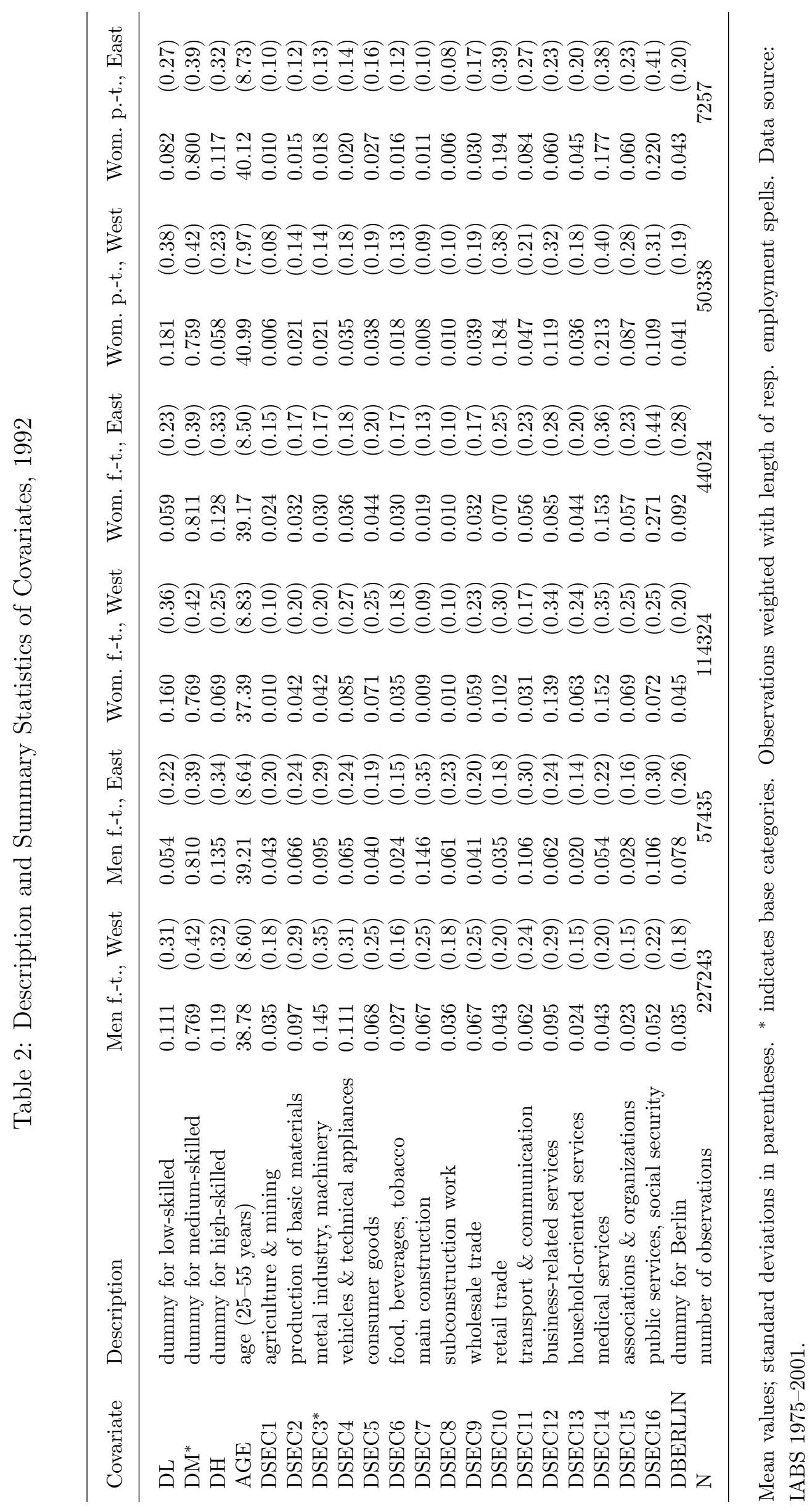




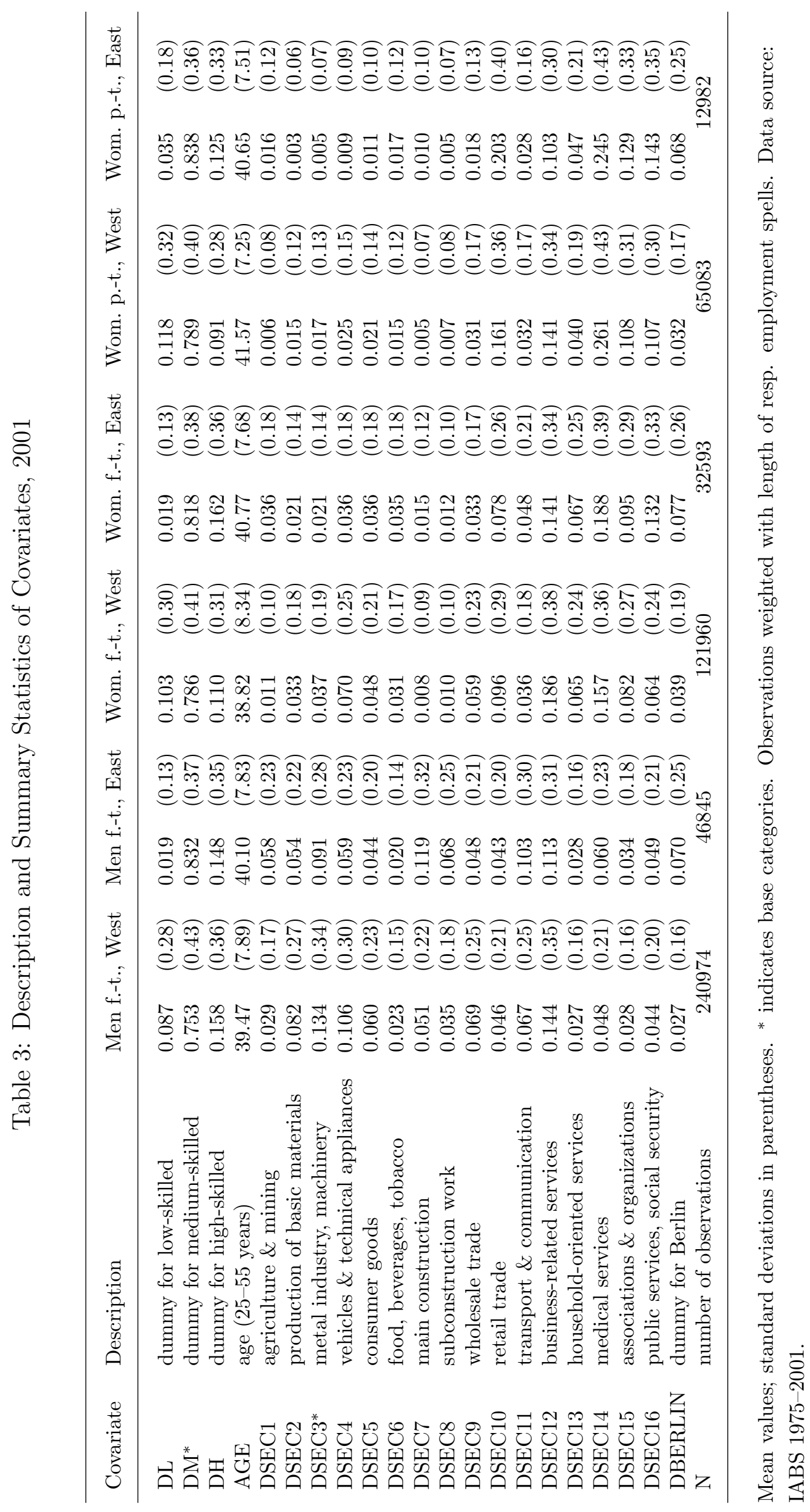


Figure 3: Regression Coefficients by Deciles in East-West Comparison: Men Working Full-Time, 1992
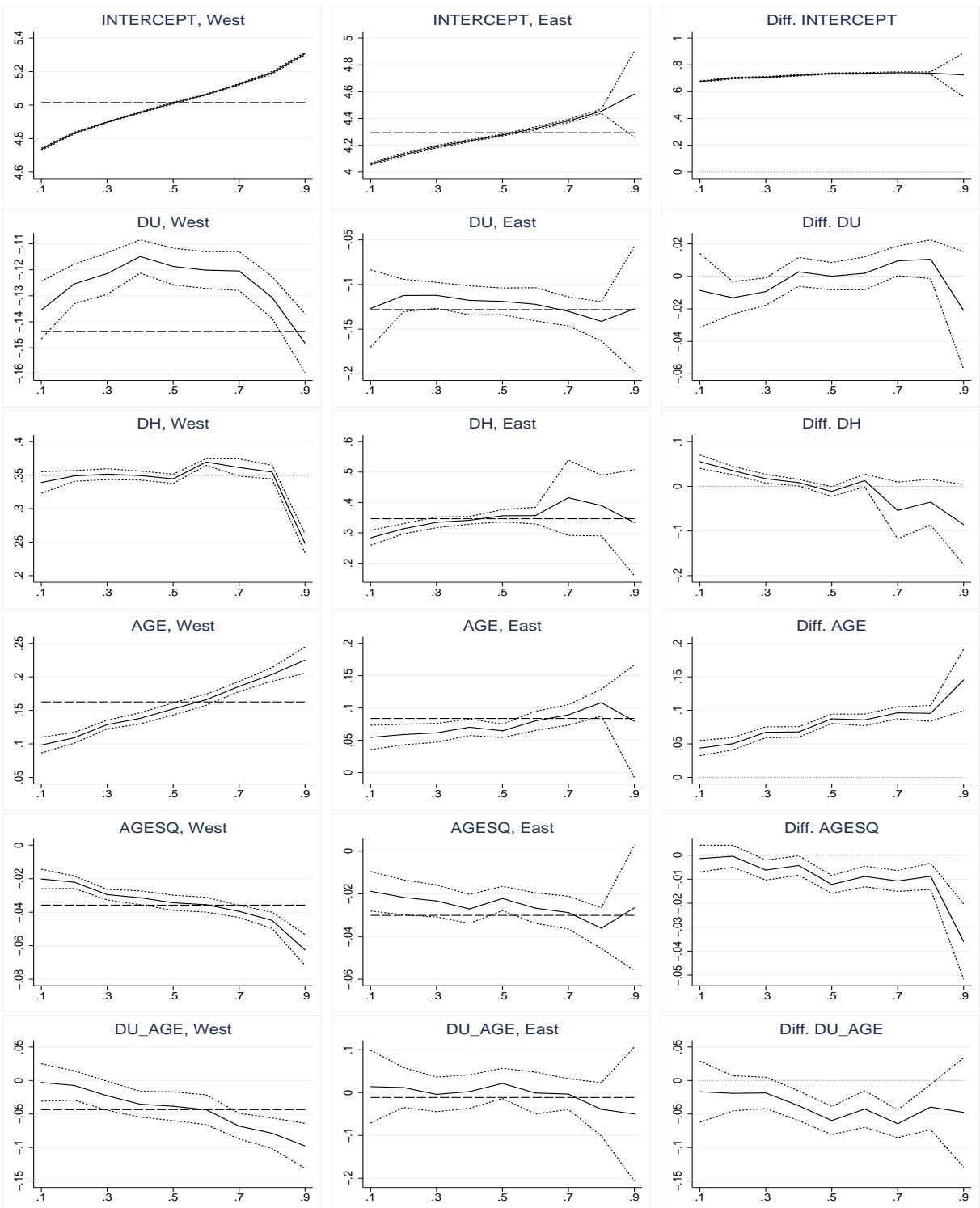

DU_AGE, Eas
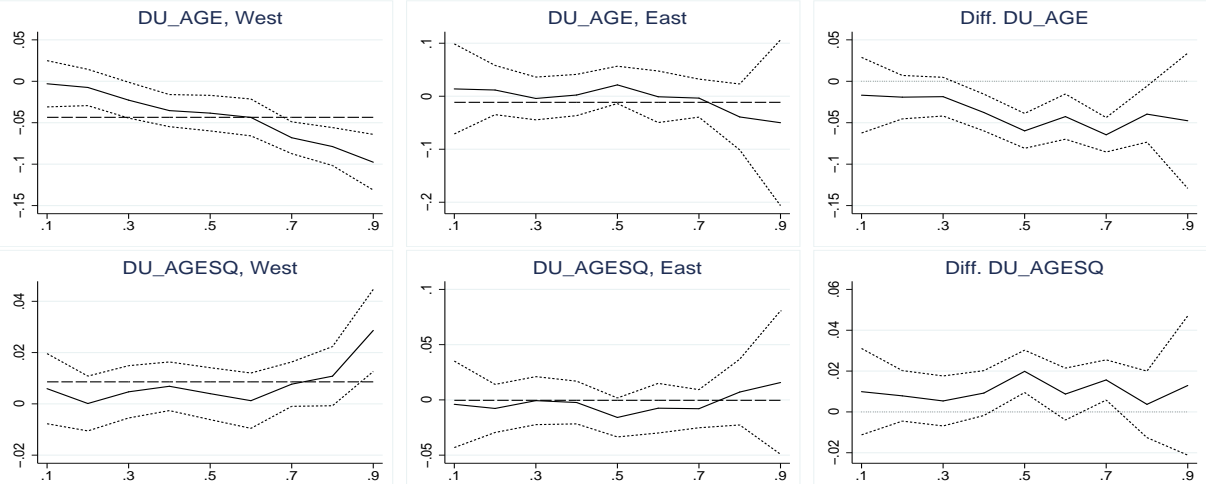

DU_AGESQ, East
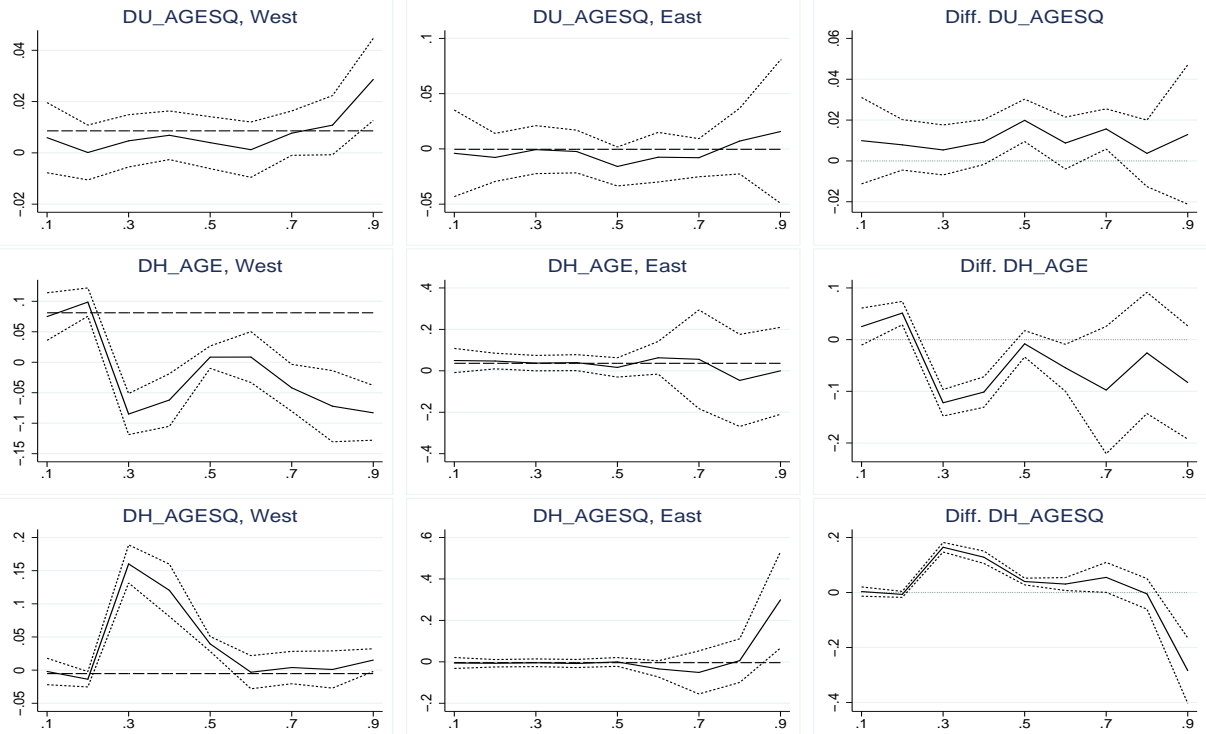

Coefficients from censored quantile regressions. Left panel: West Germany; middle panel: East Germany; right panel: West-East difference. Dashed lines: 95\% confidence bands based on 50 bootstrap resamples. Long dashed lines: Tobit regression coefficients. Data source: IABS 1975-2001. 
Figure 4: Regression Coefficients by Deciles in East-West Comparison: Women Working Full-Time, 1992
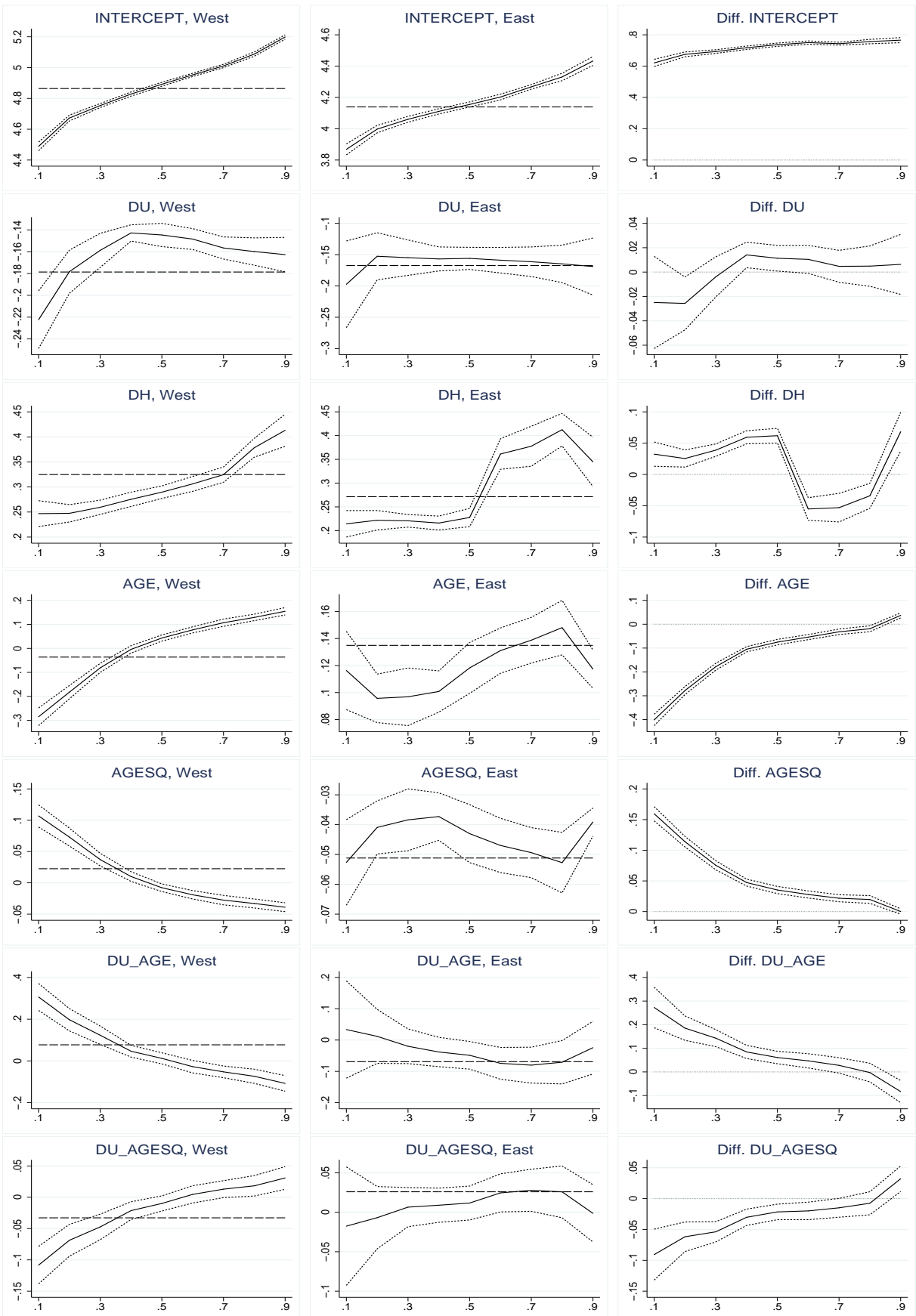

DU_AGESQ, East
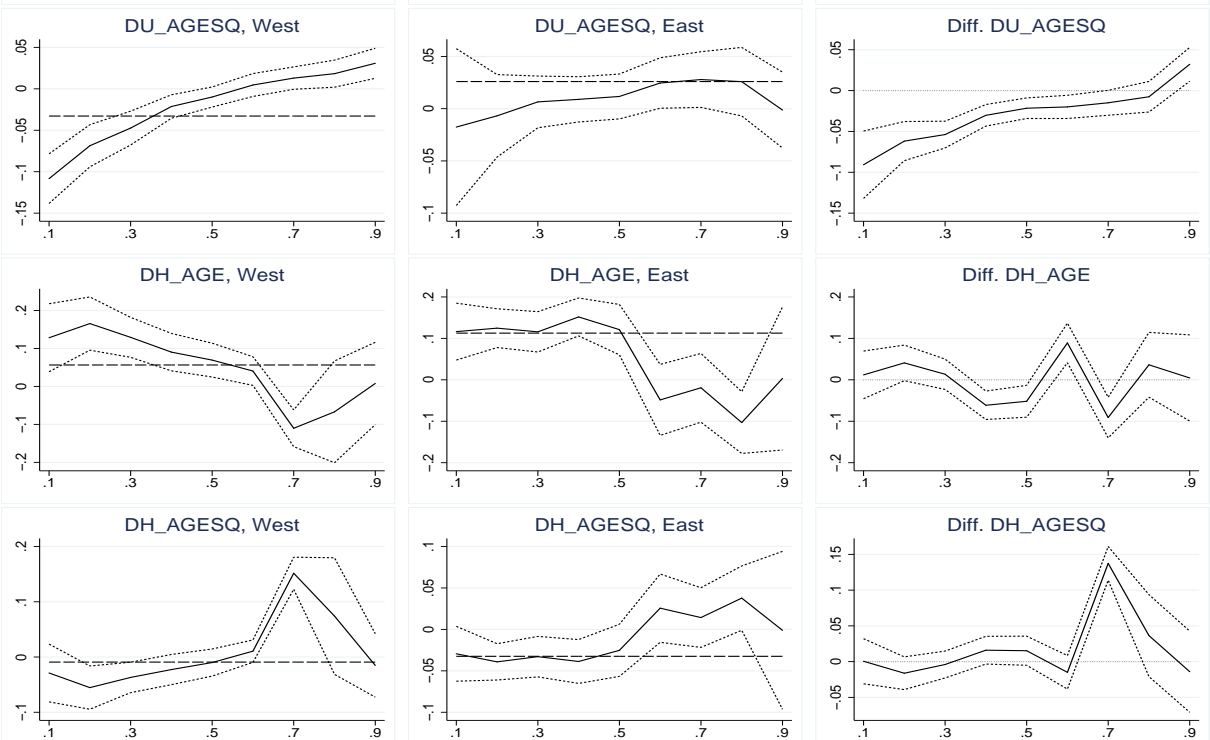

Coefficients from censored quantile regressions. Left panel: West Germany; middle panel: East Germany; right panel: West-East difference. Dashed lines: 95\% confidence bands based on 50 bootstrap resamples. Long dashed lines: Tobit regression coefficients. Data source: IABS 1975-2001. 
Figure 5: Regression Coefficients by Deciles in East-West Comparison: Women Working Part-Time, 1992
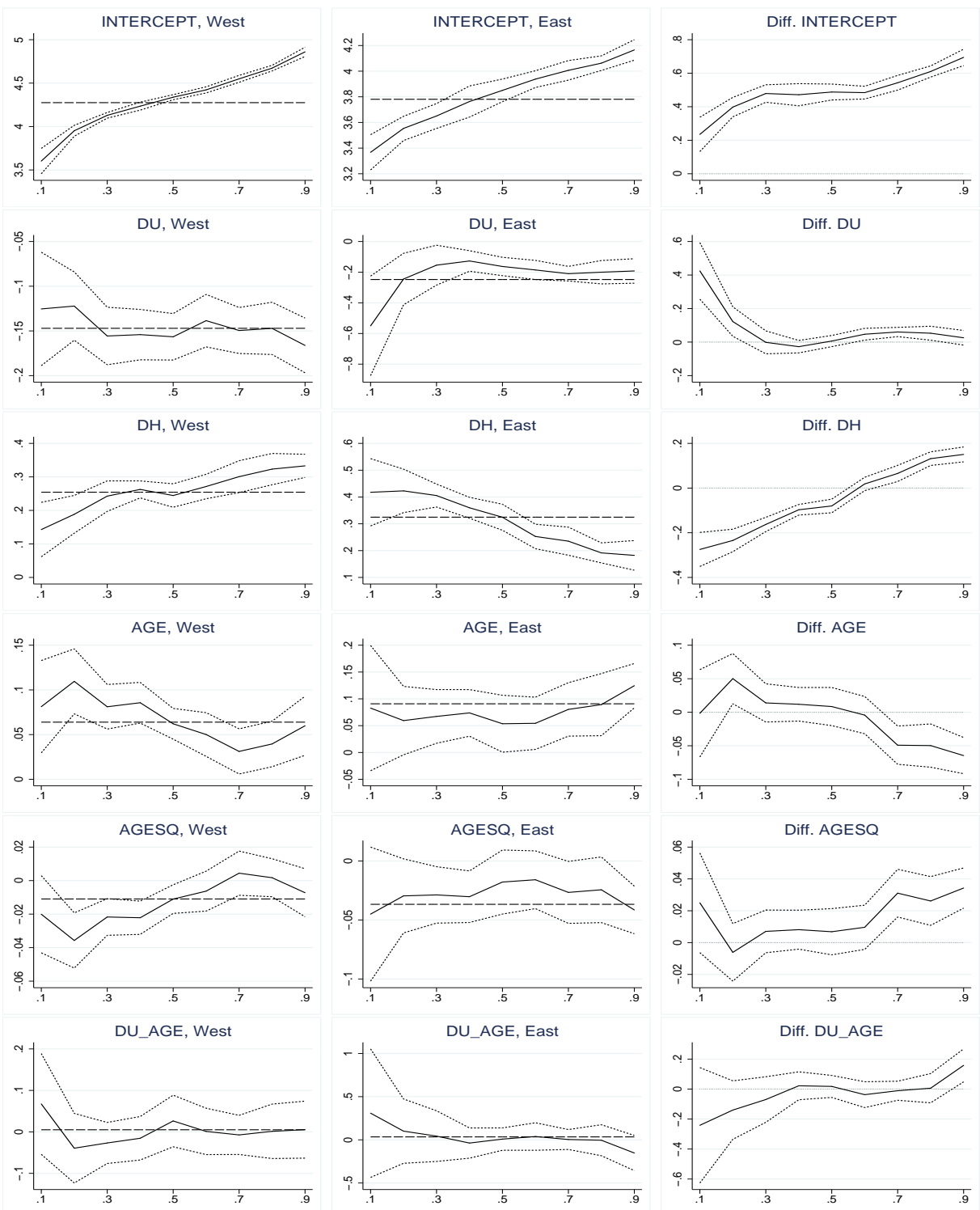

DU_AGE, East
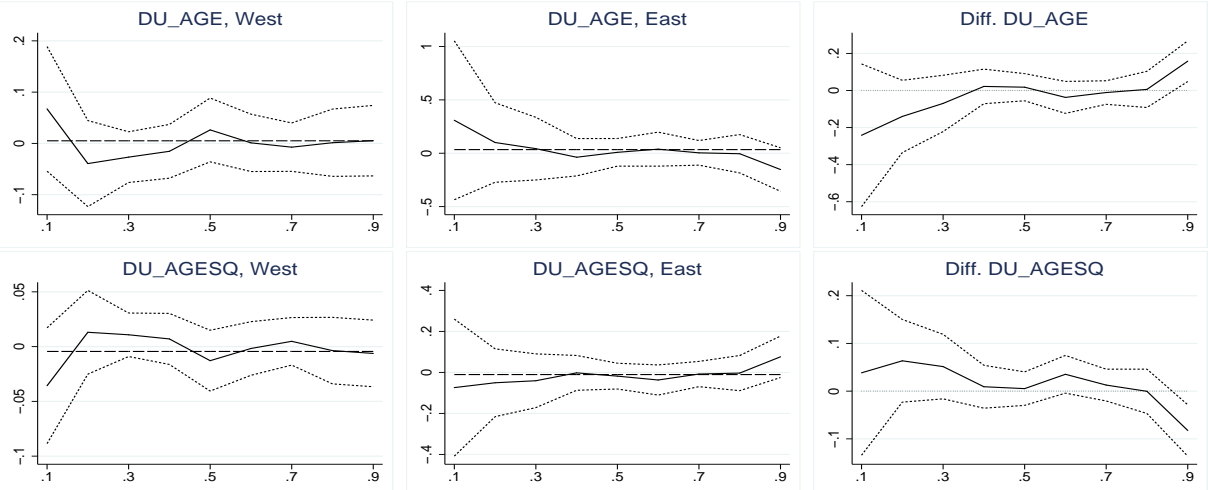

DU AGESQ, East
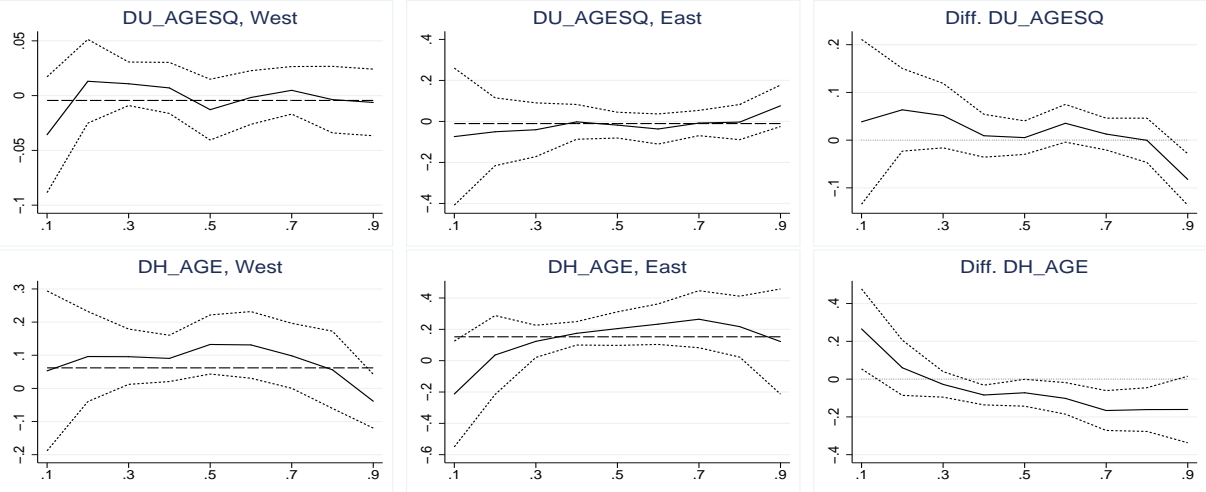

DH_AGE, East
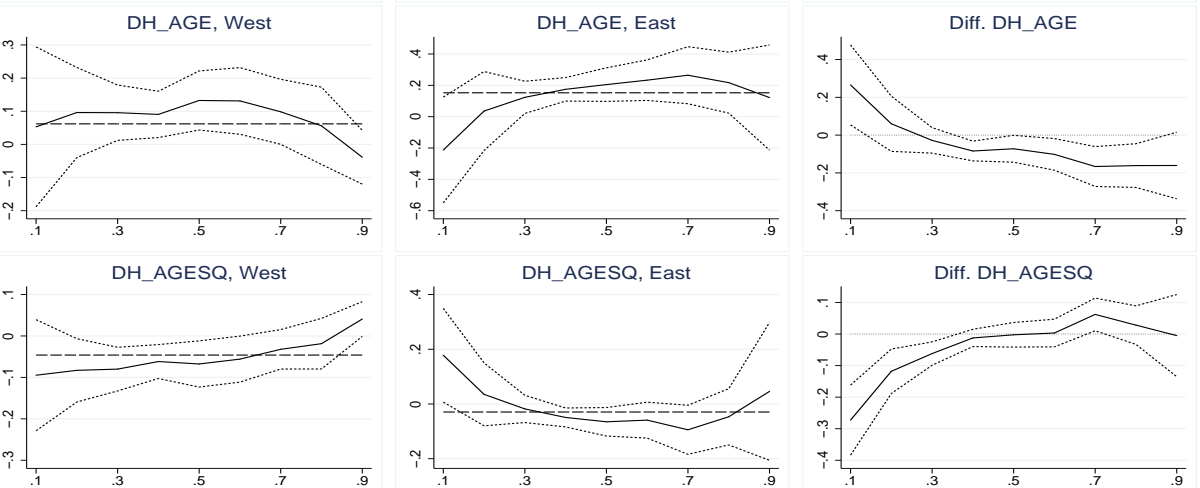

Coefficients from censored quantile regressions. Left panel: West Germany; middle panel: East Germany; right panel: West-East difference. Dashed lines: 95\% confidence bands based on 50 bootstrap resamples. Long dashed lines: Tobit regression coefficients. Data source: IABS 1975-2001. 
Figure 6: Regression Coefficients by Deciles in East-West Comparison: Men Working Full-Time, 2001
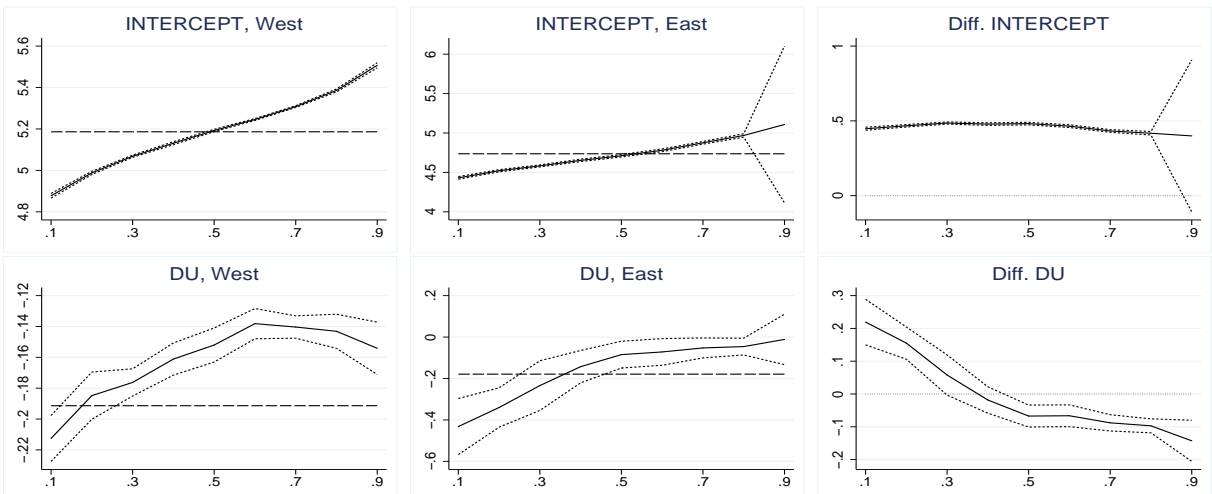

$\mathrm{DH}$, West
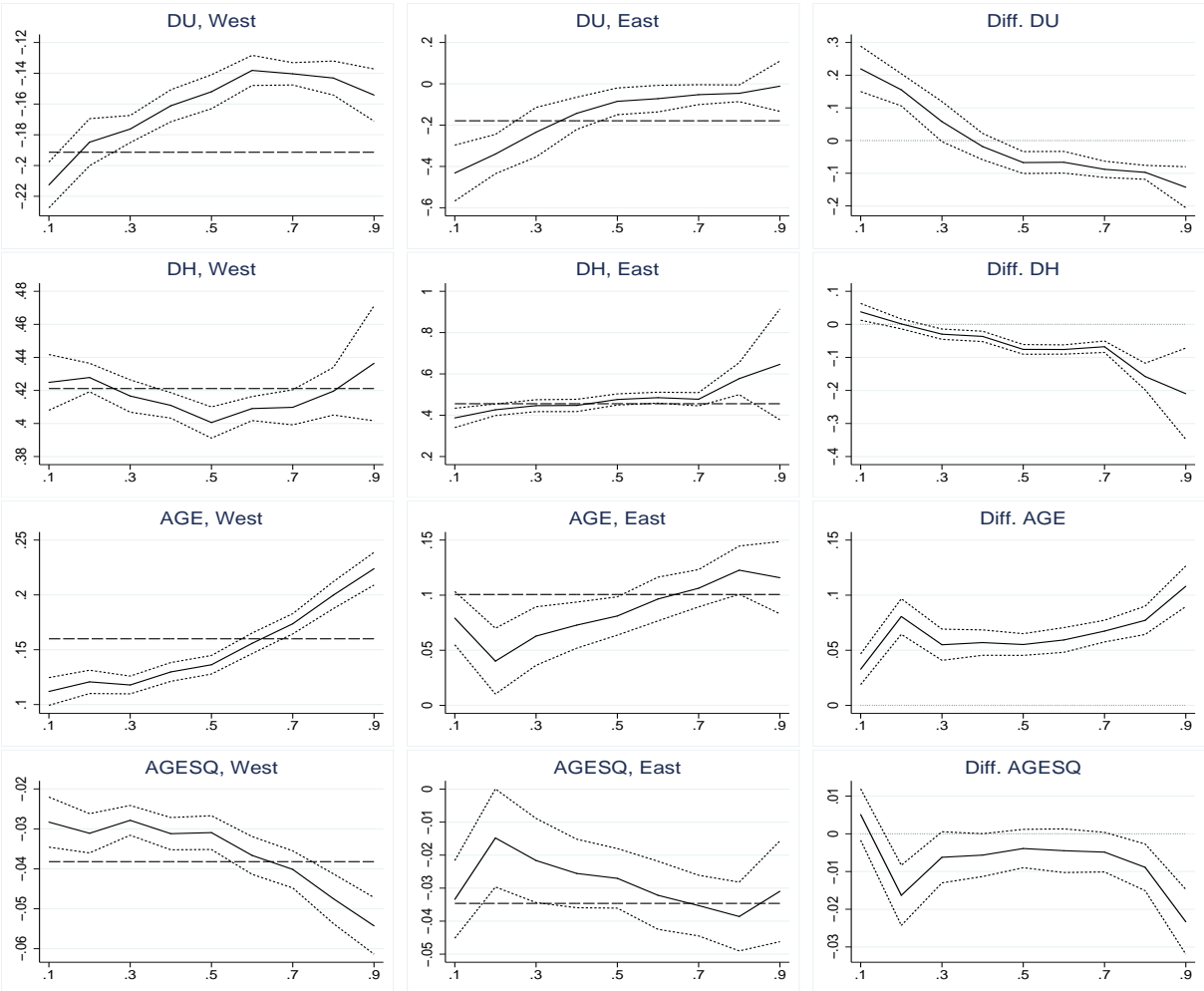

DU_AGE, West

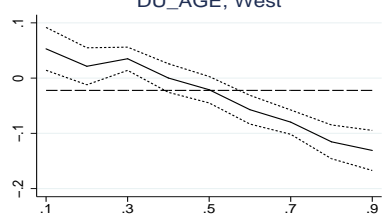

DU_AGE, East
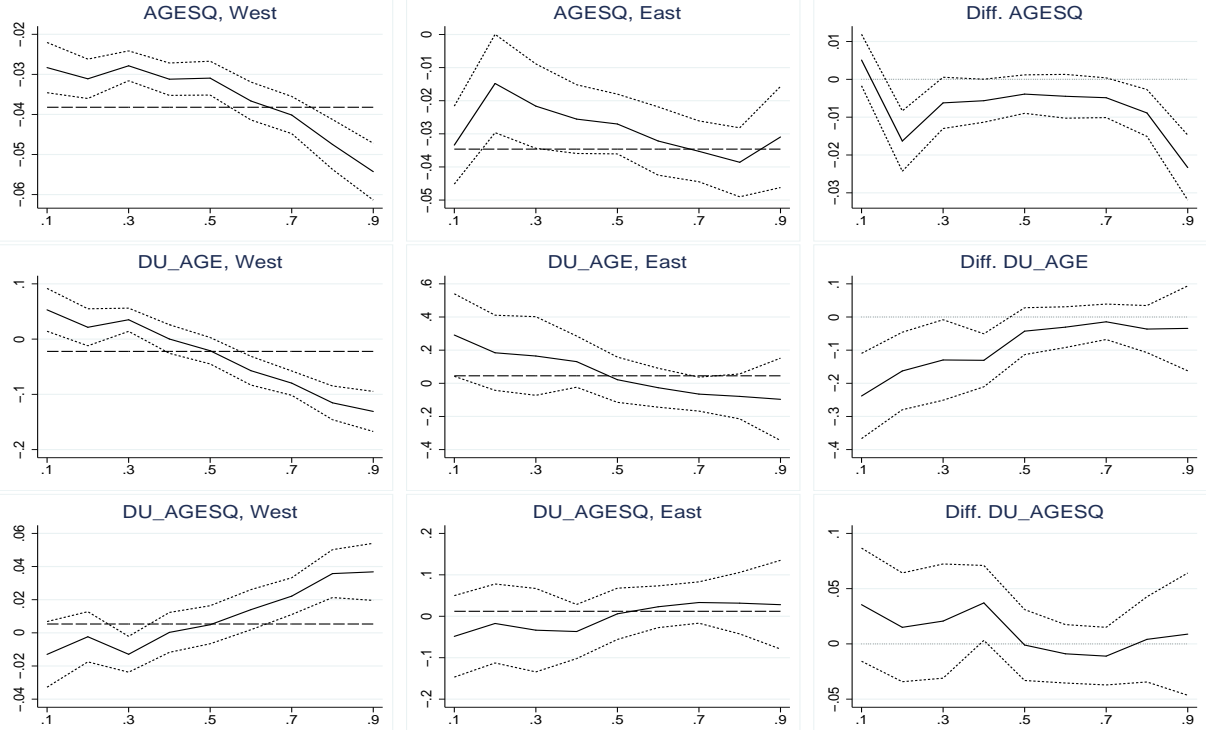

DU AGESQ, East
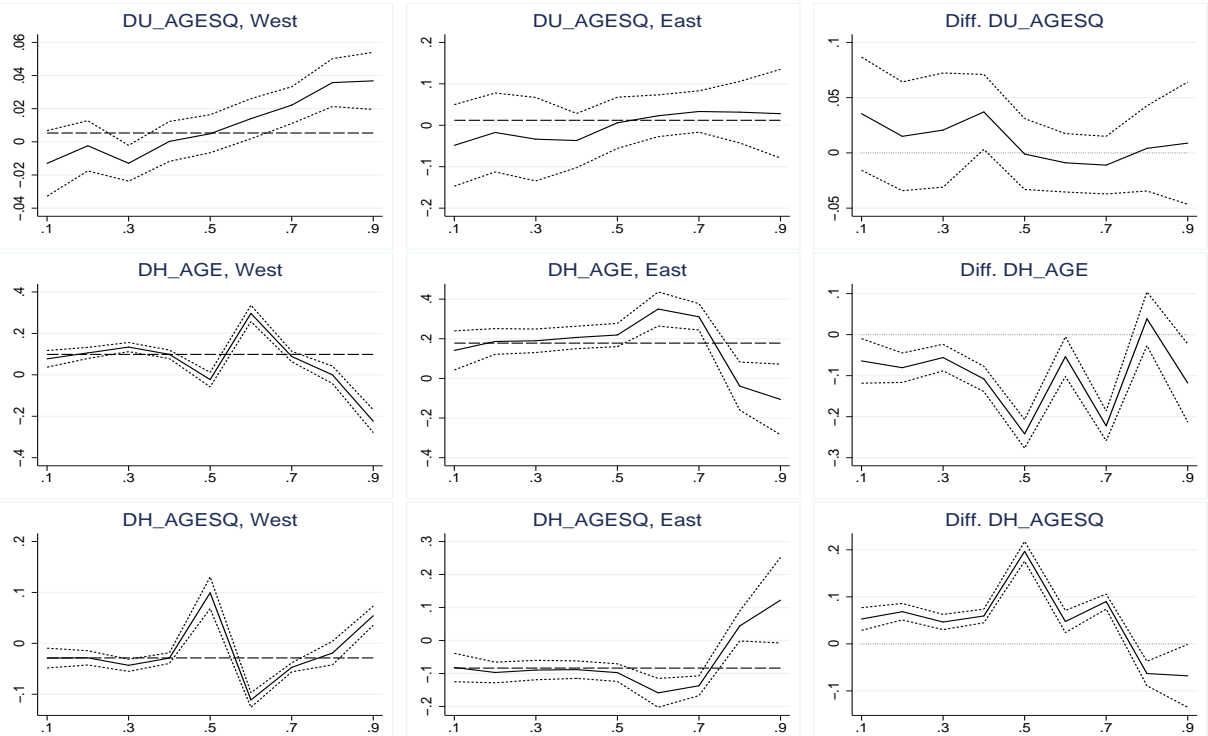

Coefficients from censored quantile regressions. Left panel: West Germany; middle panel: East Germany; right panel: West-East difference. Dashed lines: 95\% confidence bands based on 50 bootstrap resamples. Long dashed lines: Tobit regression coefficients. Data source: IABS 1975-2001. 
Figure 7: Regression Coefficients by Deciles in East-West Comparison: Women Working Full-Time, 2001
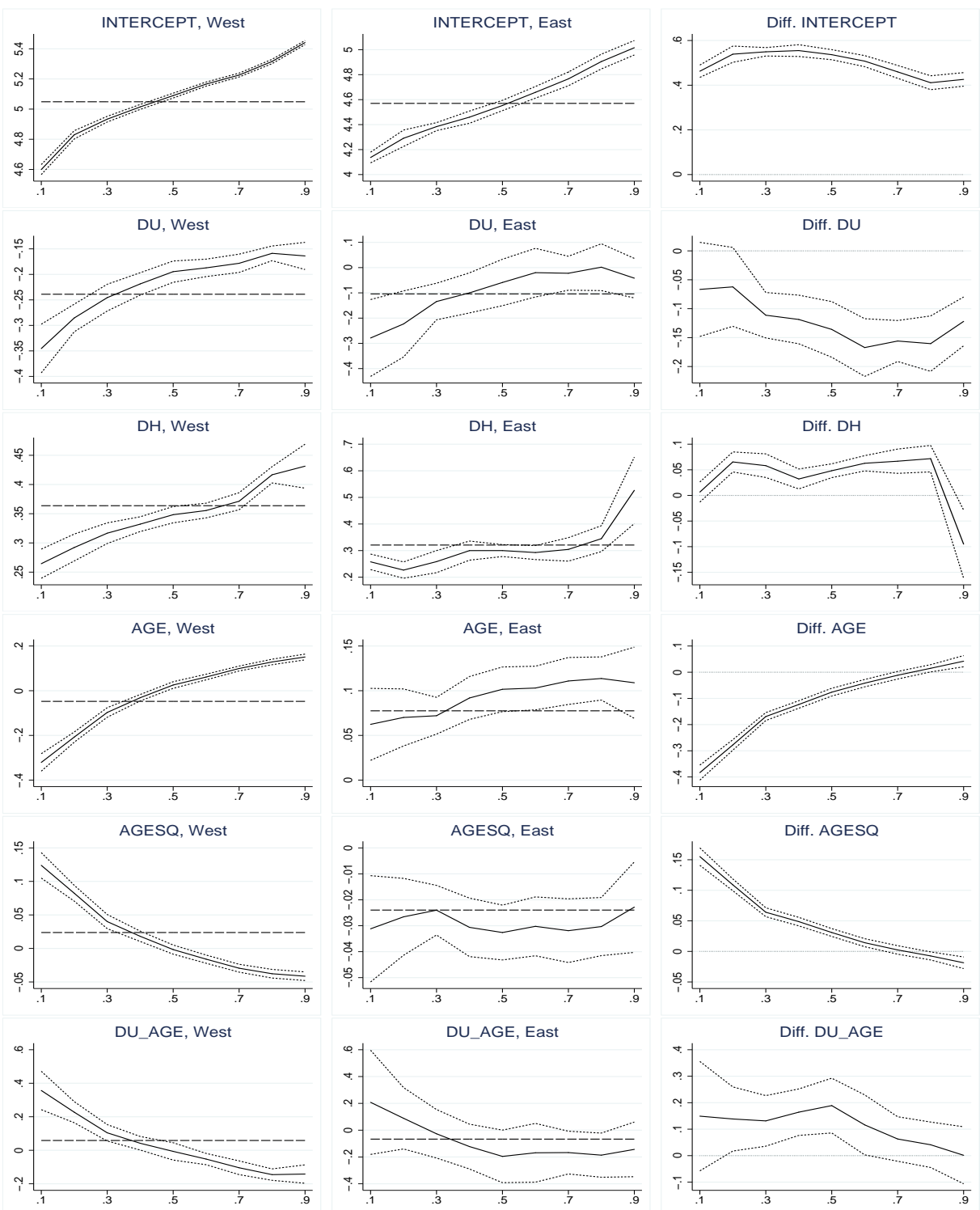

DU_AGE, East
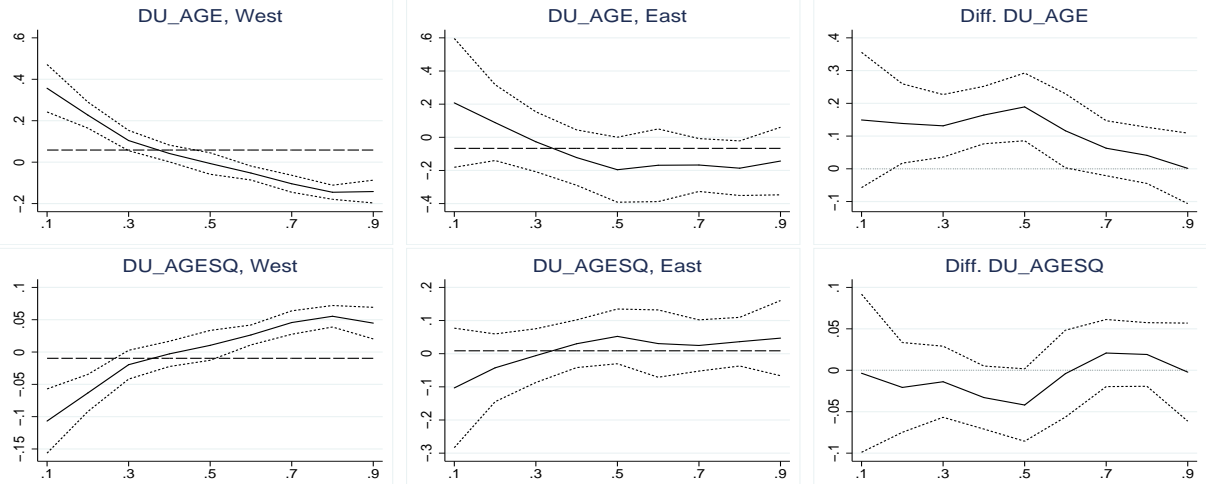

DU AGESQ, East
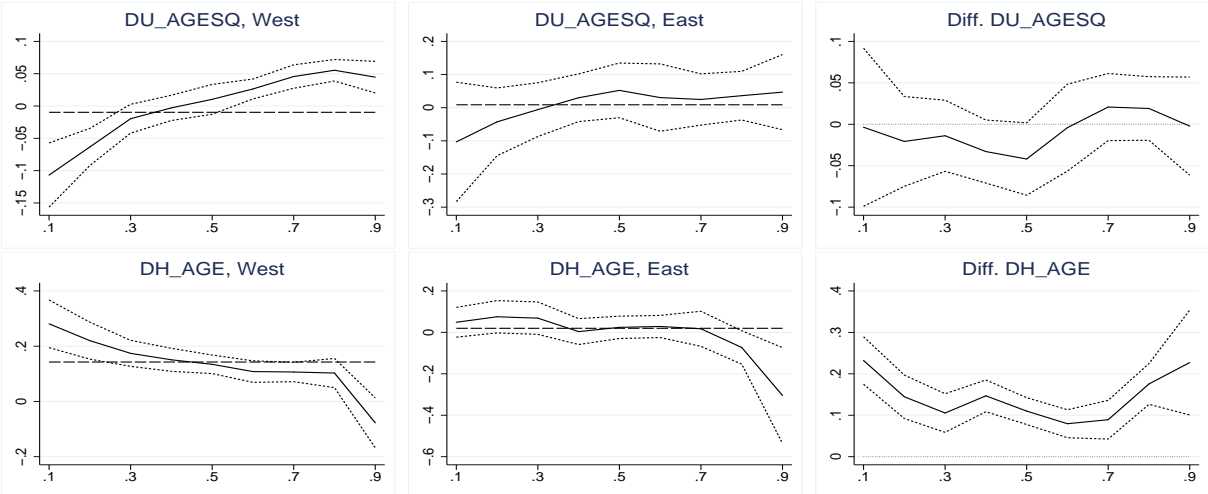

DH_AGE, East
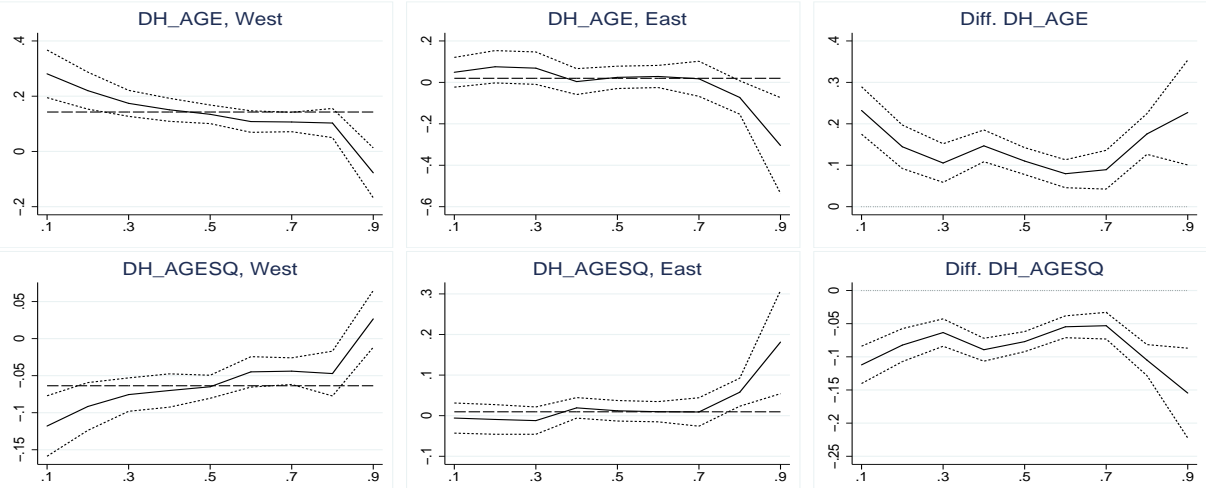

Coefficients from censored quantile regressions. Left panel: West Germany; middle panel: East Germany; right panel: West-East difference. Dashed lines: 95\% confidence bands based on 50 bootstrap resamples. Long dashed lines: Tobit regression coefficients. Data source: IABS 1975-2001. 
Figure 8: Regression Coefficients by Deciles in East-West Comparison: Women Working Part-Time, 2001
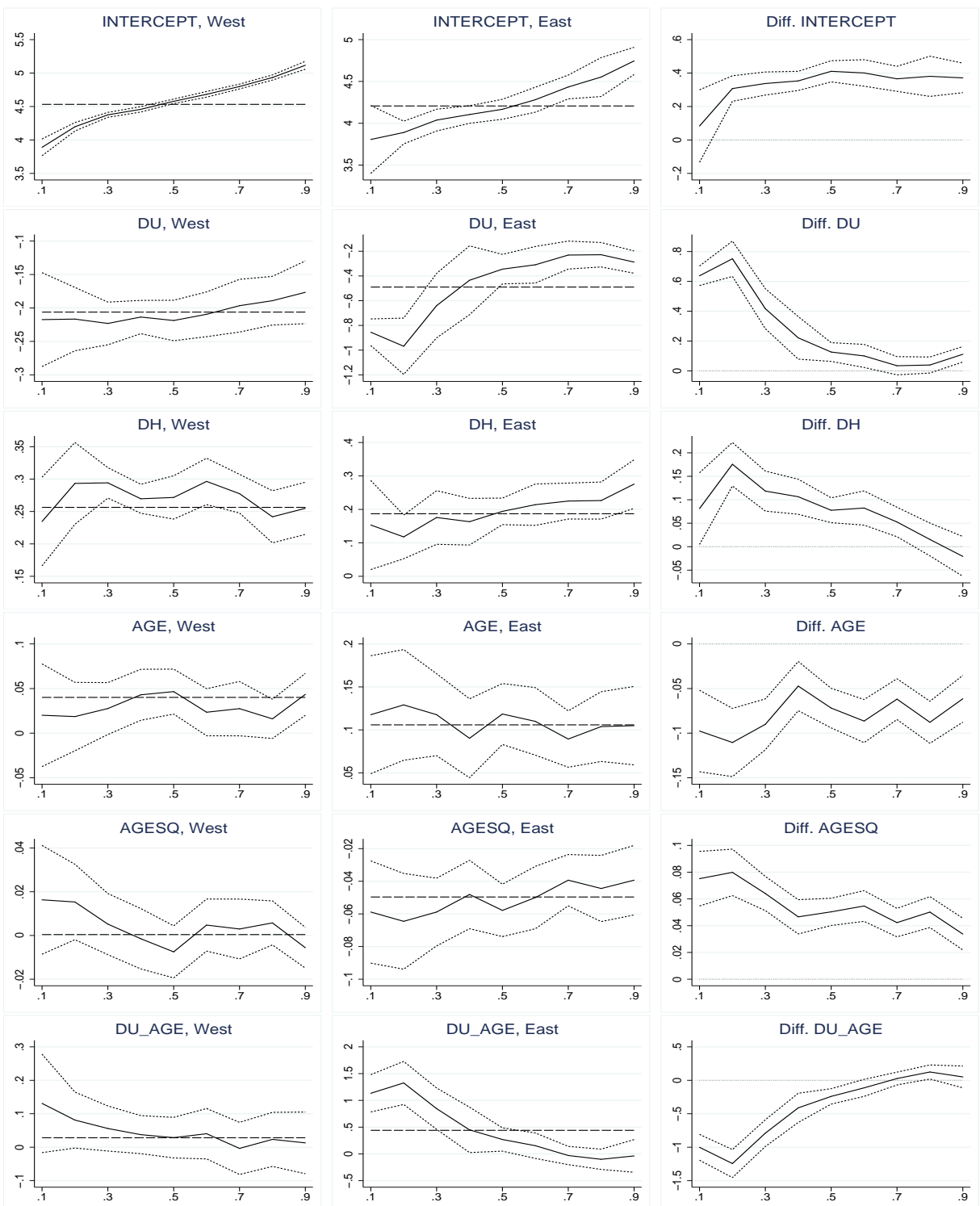

DU_AGE, East
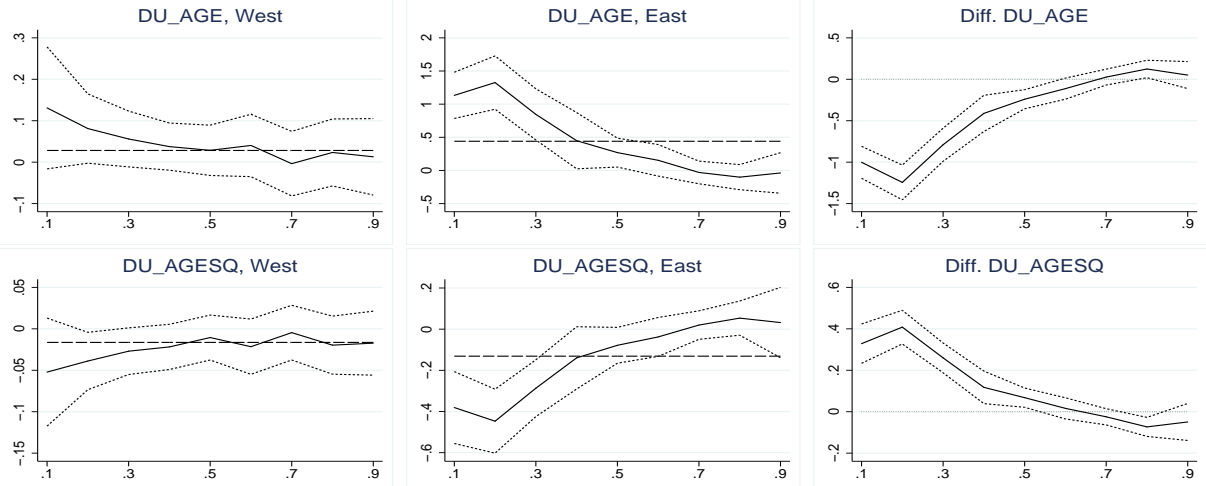

DU AGESQ, East
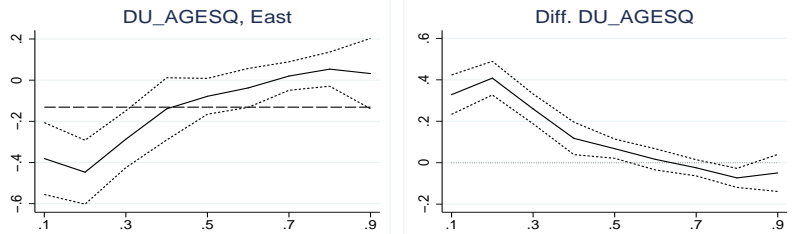

DH_AGE, West

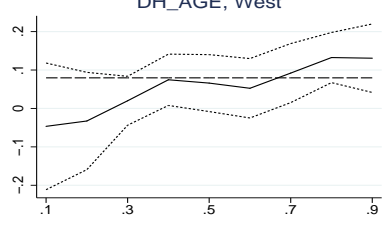

DH_AGE, East

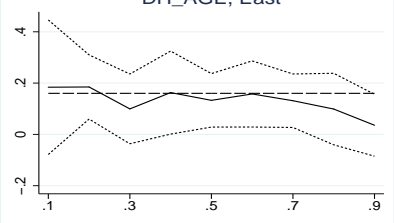

DH_AGESQ, West
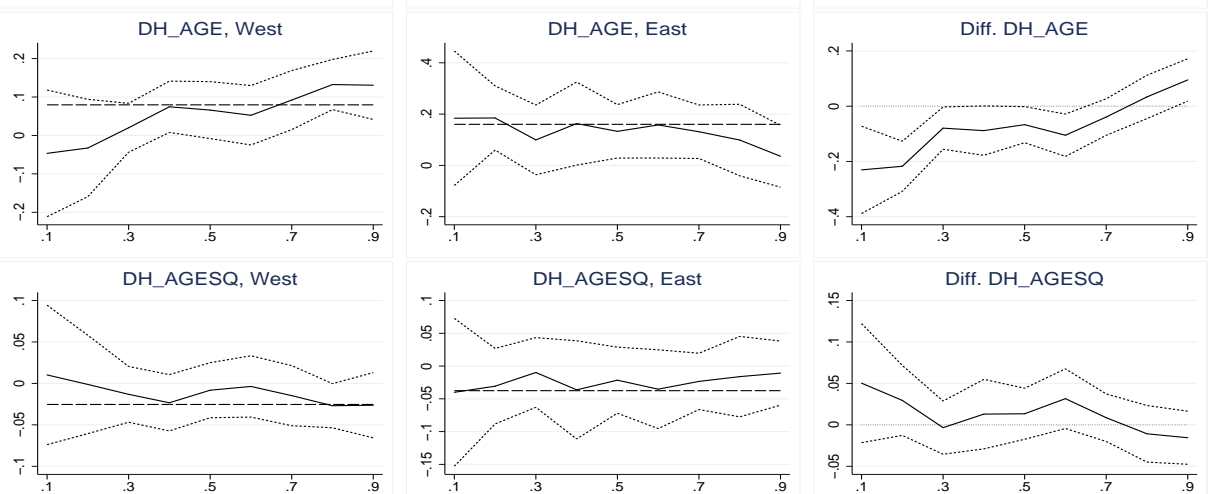

Coefficients from censored quantile regressions. Left panel: West Germany; middle panel: East Germany; right panel: West-East difference. Dashed lines: 95\% confidence bands based on 50 bootstrap resamples. Long dashed lines: Tobit regression coefficients. Data source: IABS 1975-2001. 
Figure 9: Regression Coefficients by Deciles in Comparison over Time: Men Working Full-Time, West
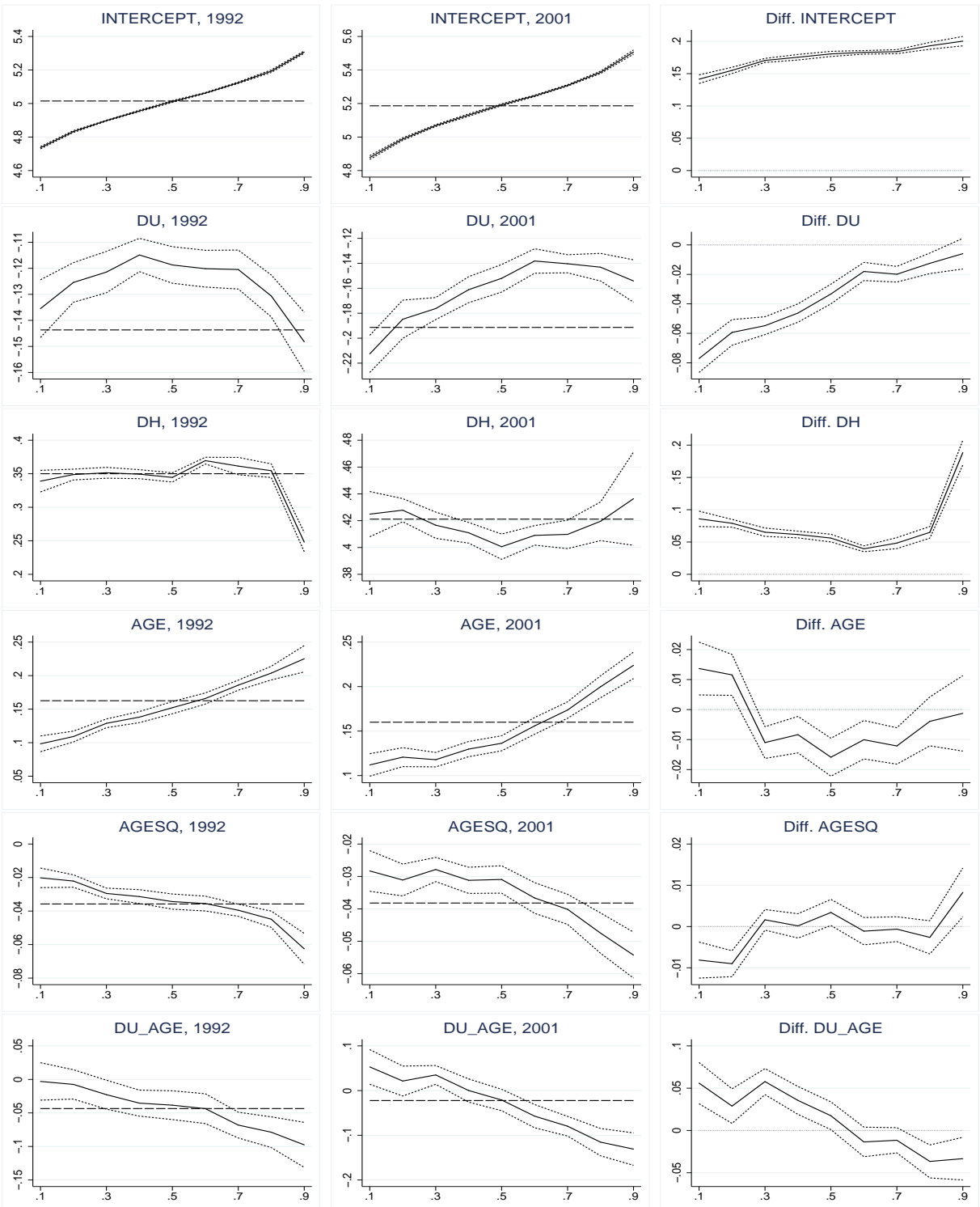

DU_AGE, 2001
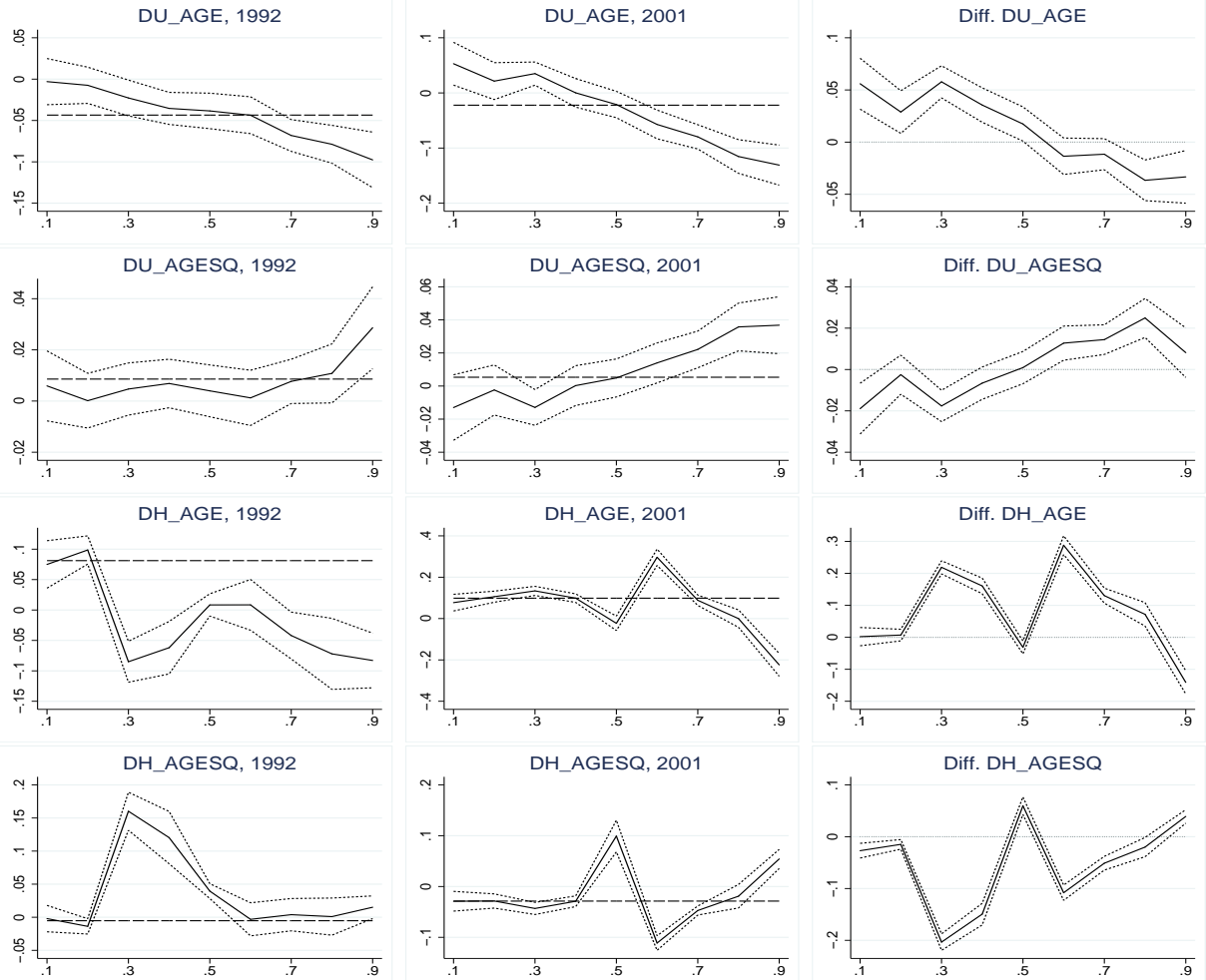

Coefficients from censored quantile regressions. Left panel: 1992; middle panel: 2001; right panel: difference 2001-1992. Dashed lines: 95\% confidence bands based on 50 bootstrap resamples. Long dashed lines: Tobit regression coefficients. Data source: IABS 1975-2001. 
Figure 10: Regression Coefficients by Deciles in Comparison over Time: Women Working Full-Time, West
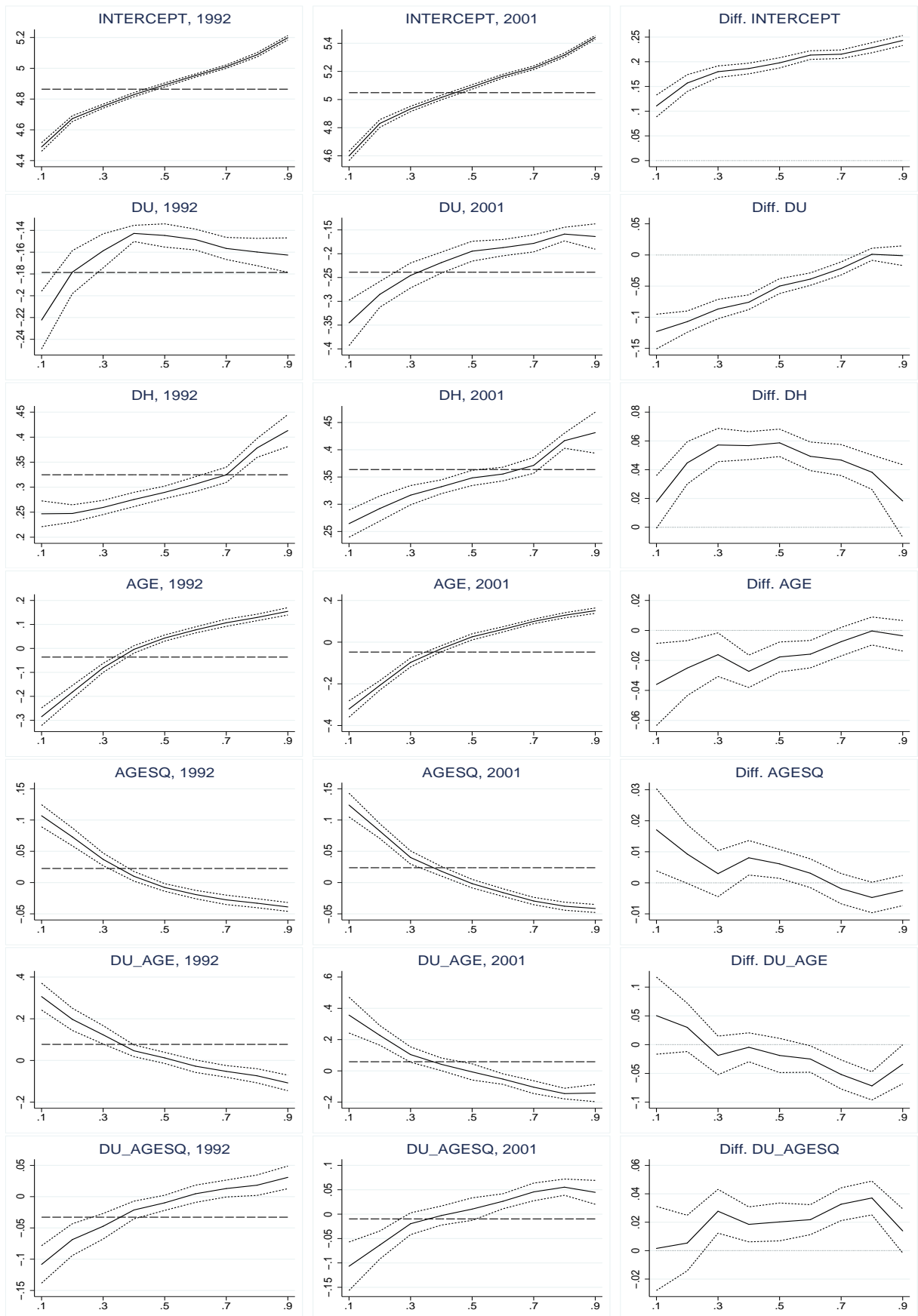

DU_AGESQ, 2001
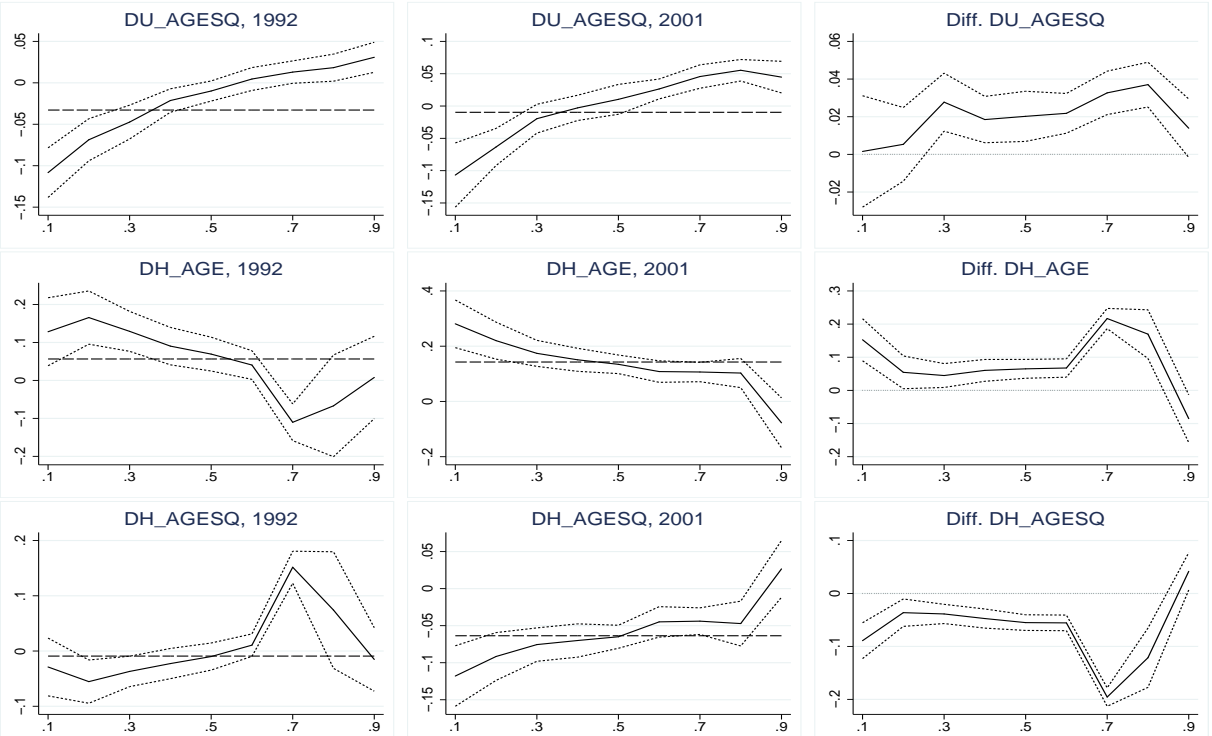

Coefficients from censored quantile regressions. Left panel: 1992; middle panel: 2001; right panel: difference 2001-1992. Dashed lines: 95\% confidence bands based on 50 bootstrap resamples. Long dashed lines: Tobit regression coefficients. Data source: IABS 1975-2001. 
Figure 11: Regression Coefficients by Deciles in Comparison over Time: Women Working Part-Time, West
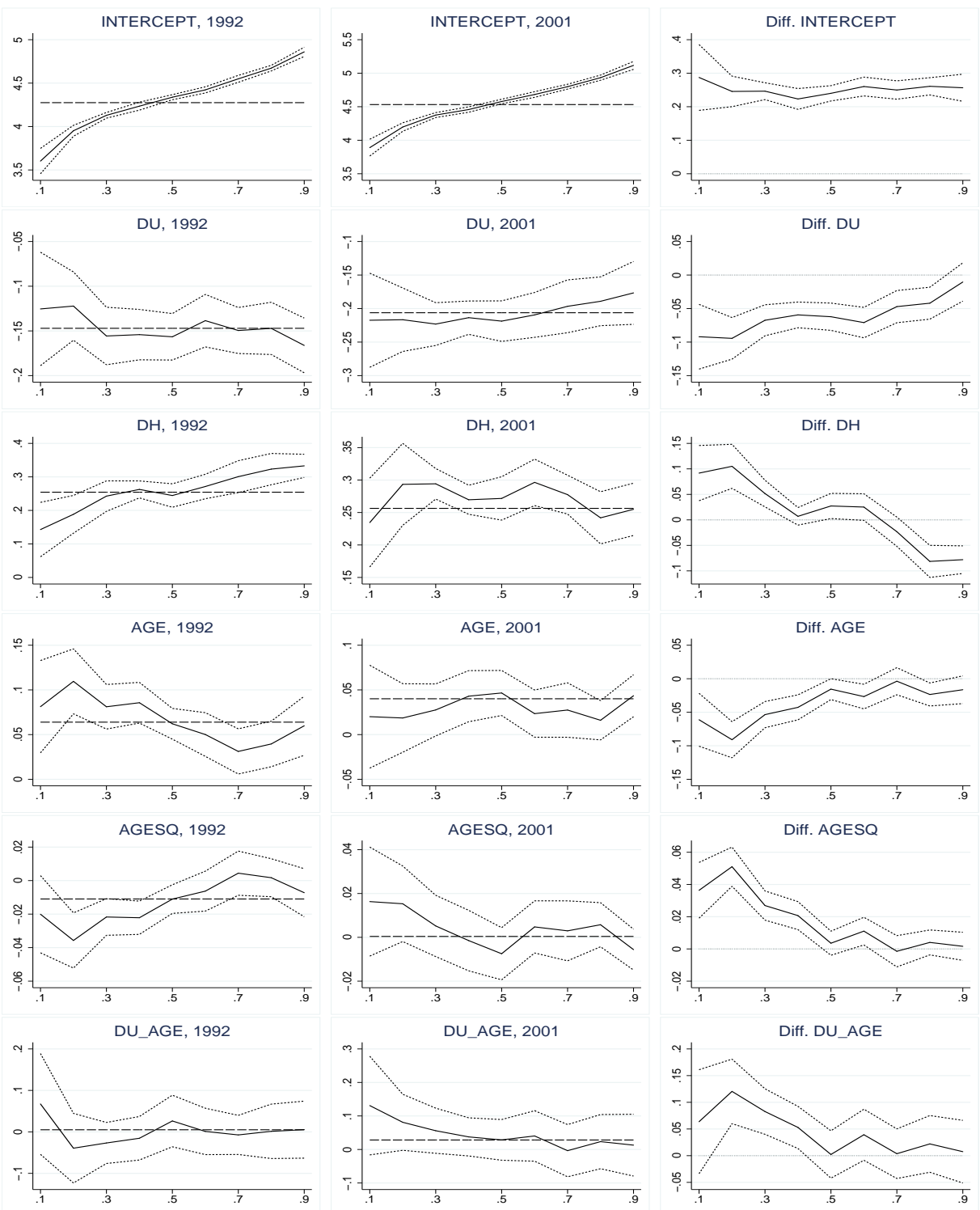

DU_AGE, 2001
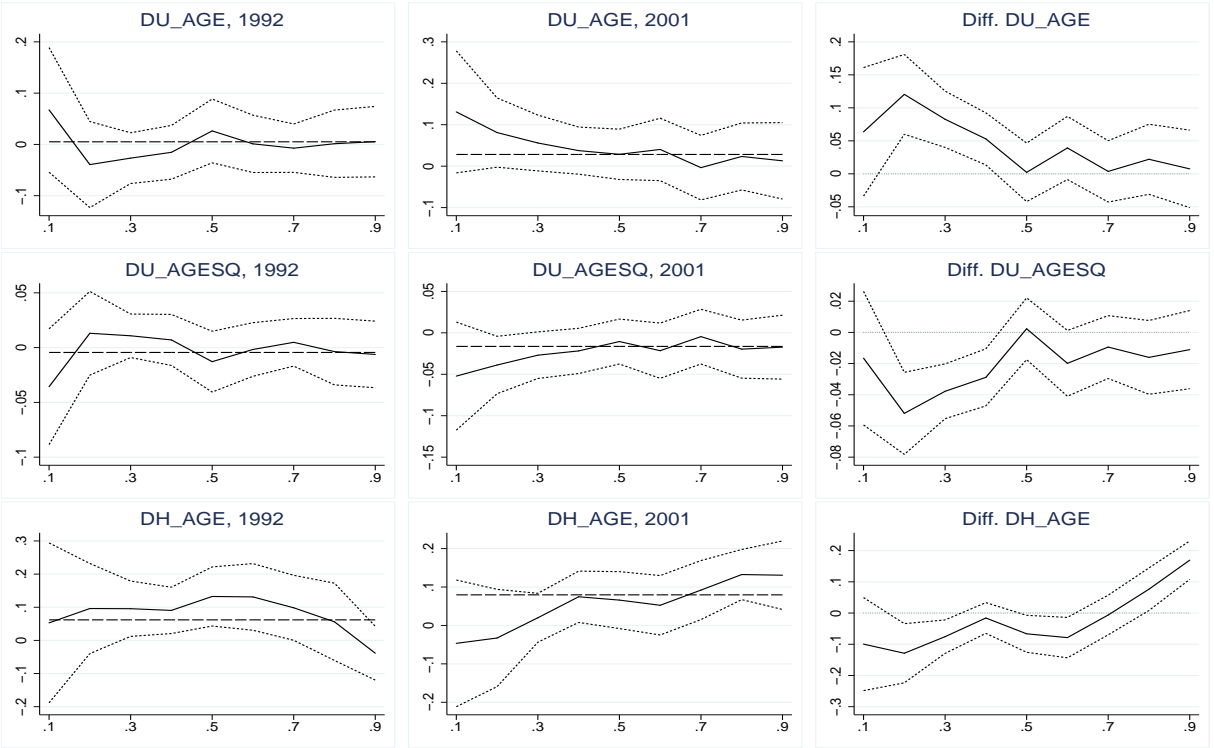

DH_AGE, 2001
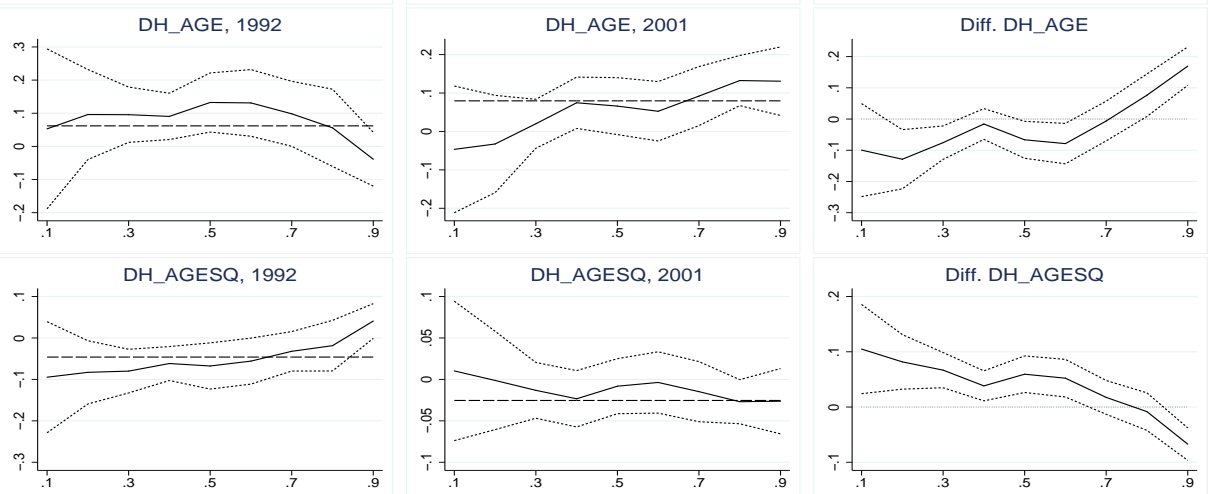

Coefficients from censored quantile regressions. Left panel: 1992; middle panel: 2001; right panel: difference 2001-1992. Dashed lines: 95\% confidence bands based on 50 bootstrap resamples. Long dashed lines: Tobit regression coefficients. Data source: IABS 1975-2001. 
Figure 12: Regression Coefficients by Deciles in Comparison over Time: Men Working Full-Time, East
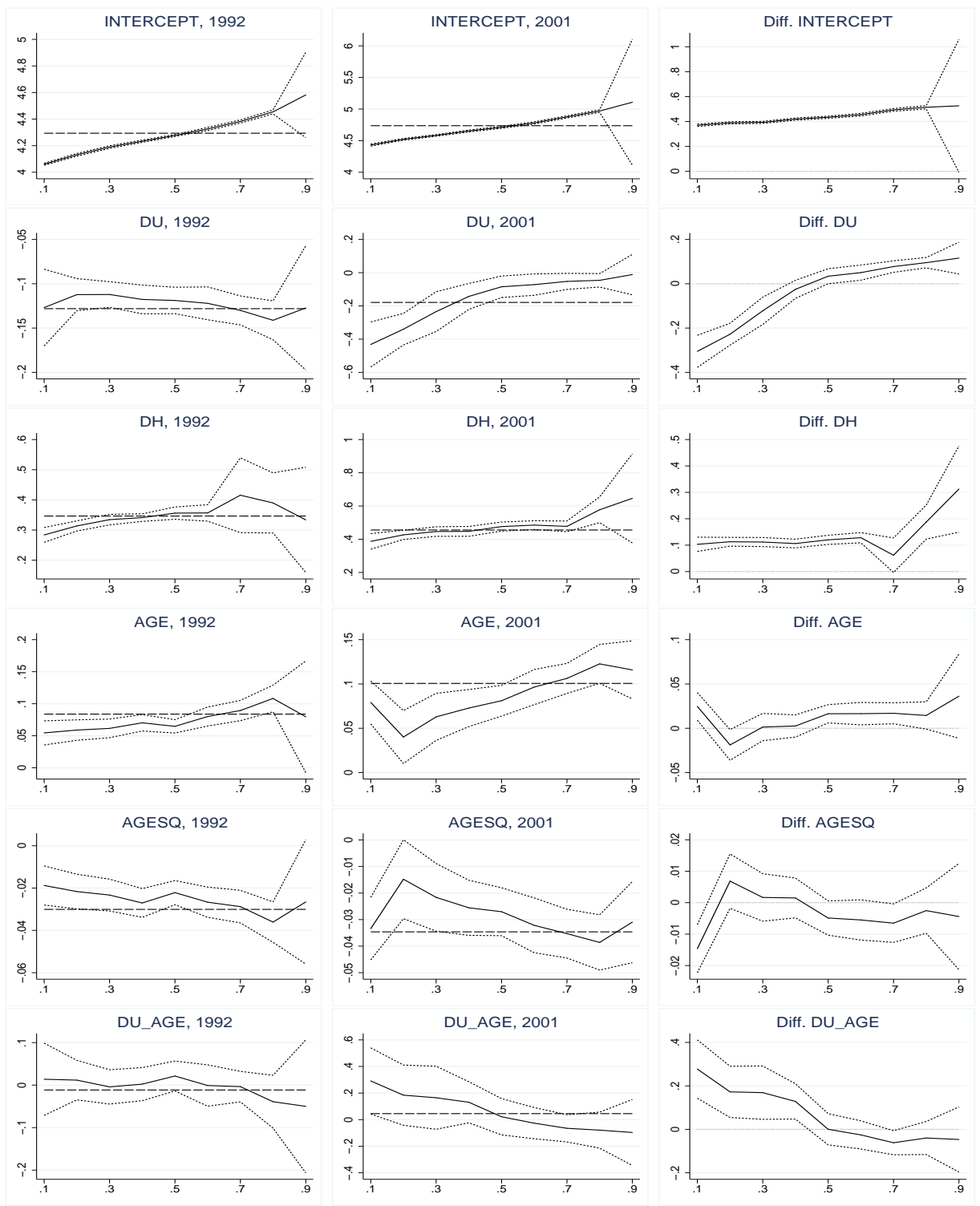

DU_AGE, 2001
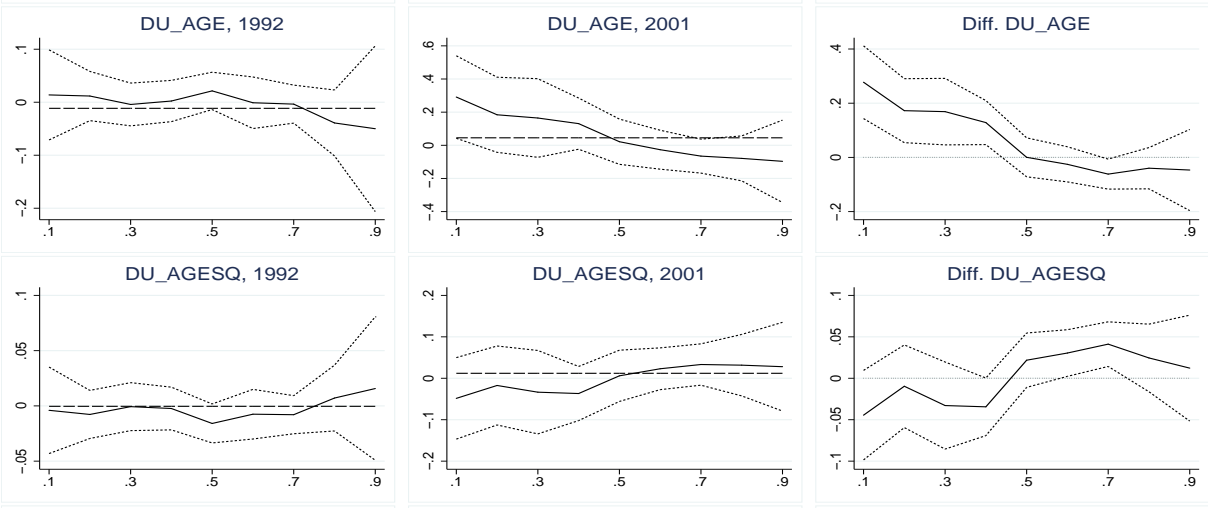

DU_AGESQ, 2001
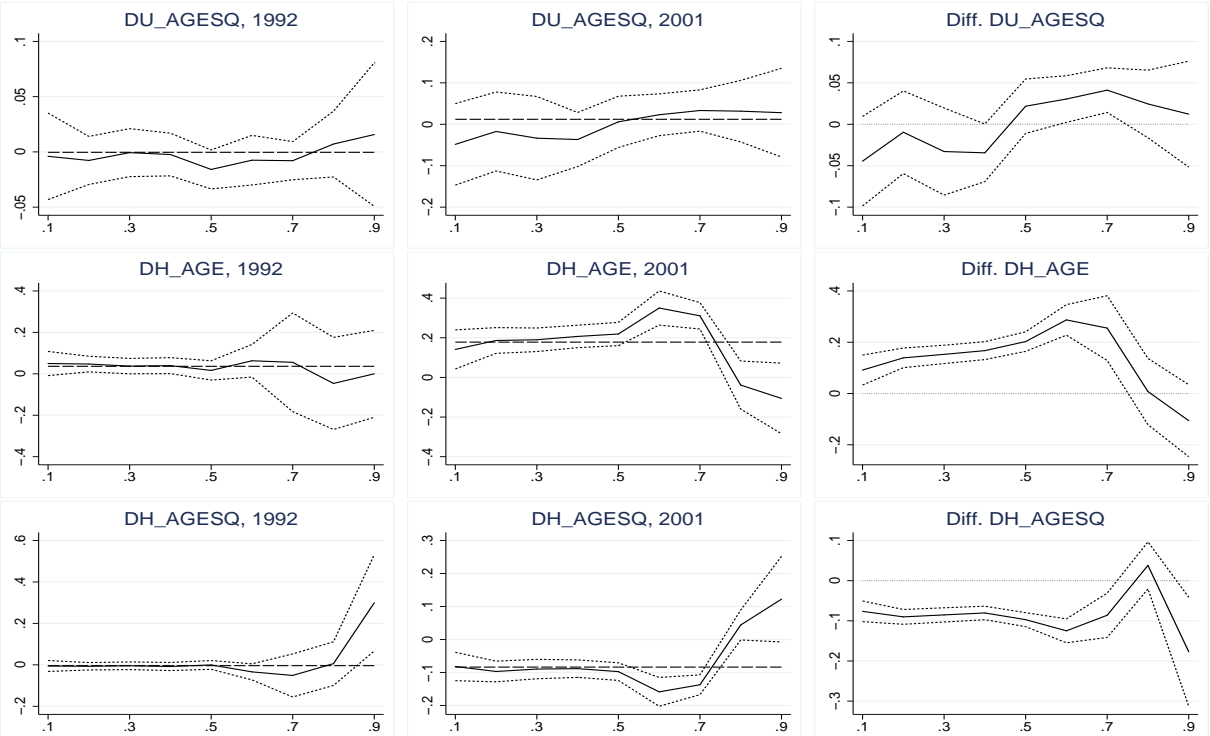

Coefficients from censored quantile regressions. Left panel: 1992; middle panel: 2001; right panel: difference 2001-1992. Dashed lines: 95\% confidence bands based on 50 bootstrap resamples. Long dashed lines: Tobit regression coefficients. Data source: IABS 1975-2001. 
Figure 13: Regression Coefficients by Deciles in Comparison over Time: Women Working Full-Time, East
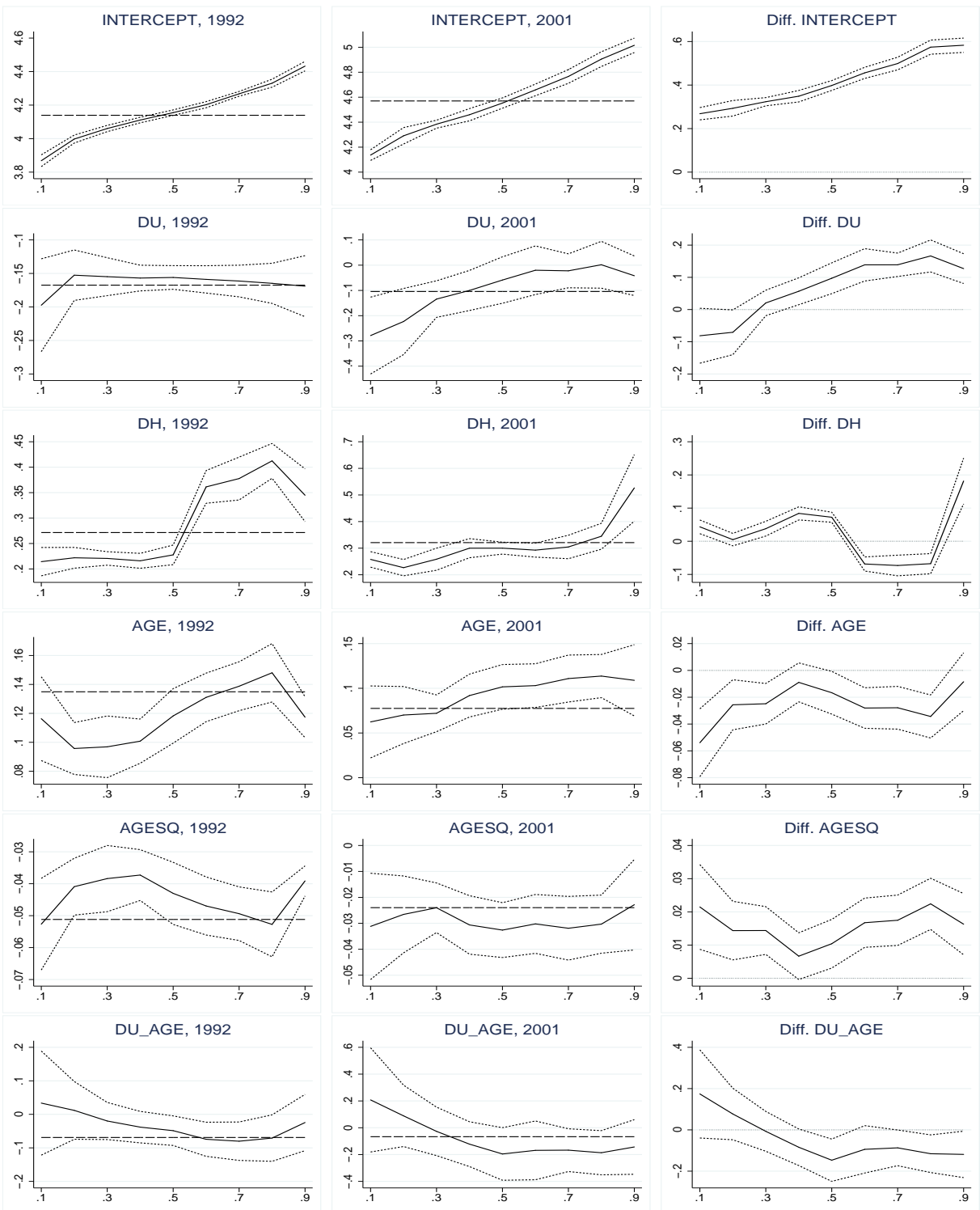

DU_AGE, 2001
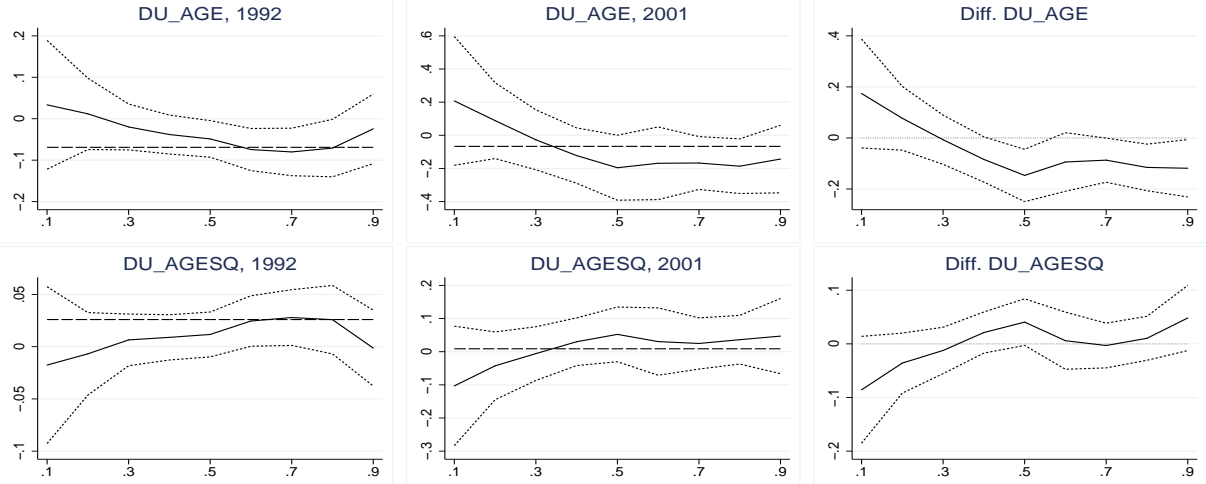

DU AGESQ, 2001
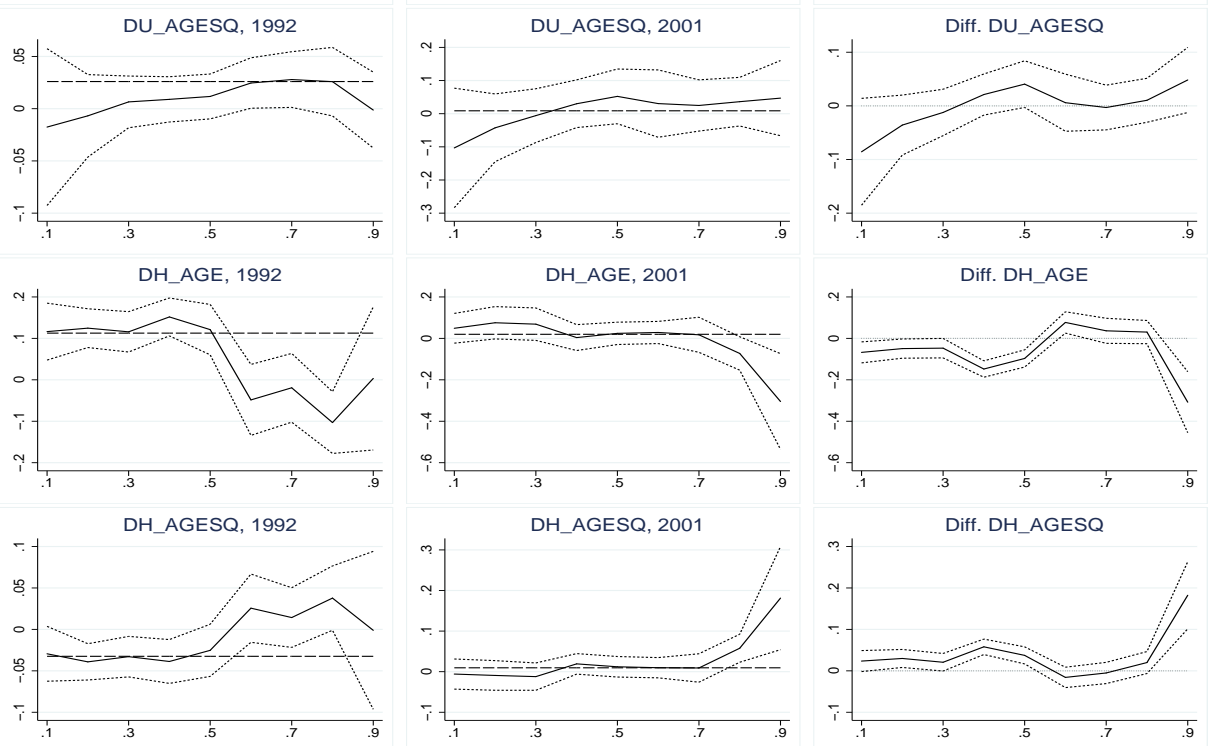

Coefficients from censored quantile regressions. Left panel: 1992; middle panel: 2001; right panel: difference 2001-1992. Dashed lines: 95\% confidence bands based on 50 bootstrap resamples. Long dashed lines: Tobit regression coefficients. Data source: IABS 1975-2001. 
Figure 14: Regression Coefficients by Deciles in Comparison over Time: Women Working Part-Time, East
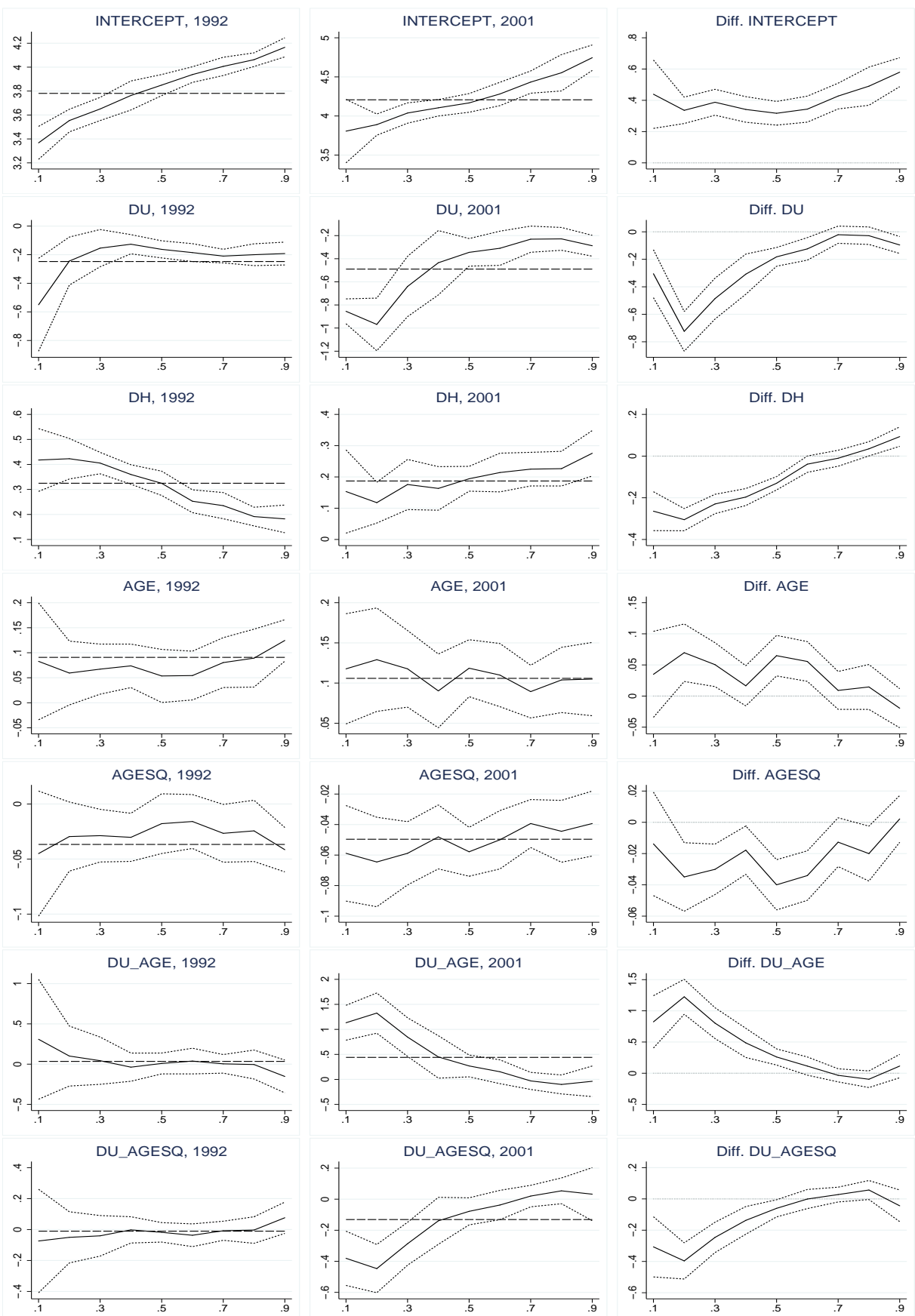

DU_AGESQ, 2001
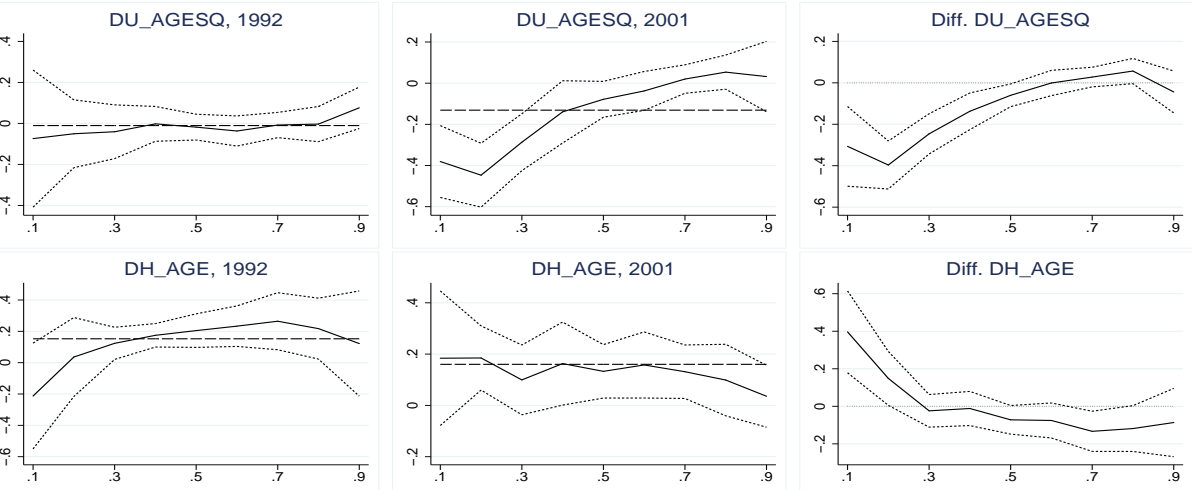

DH_AGE, 2001
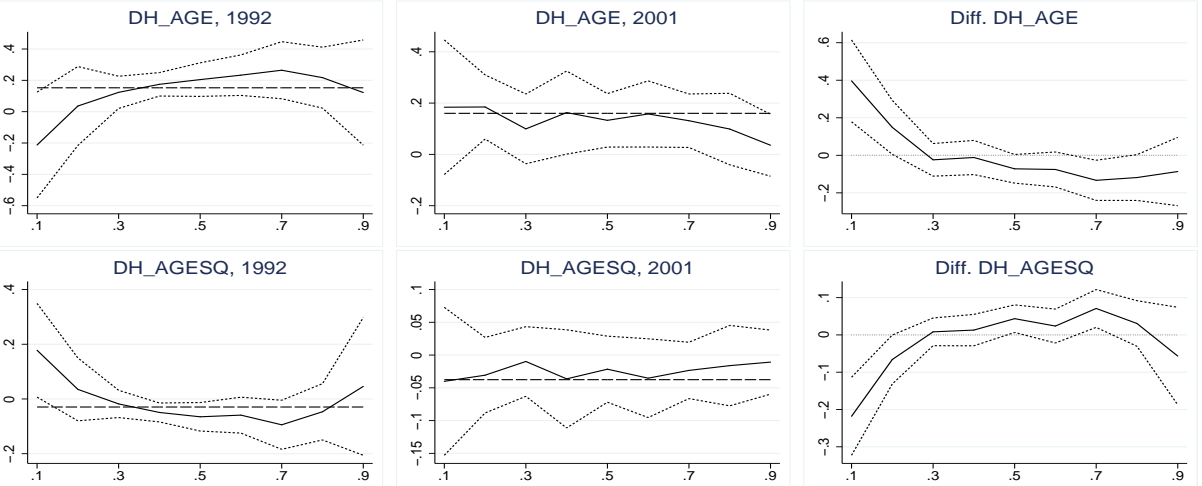

Coefficients from censored quantile regressions. Left panel: 1992; middle panel: 2001; right panel: difference 2001-1992. Dashed lines: 95\% confidence bands based on 50 bootstrap resamples. Long dashed lines: Tobit regression coefficients. Data source: IABS 1975-2001. 
Figure 15: Median Age-Earnings Profiles for Different Skill Groups
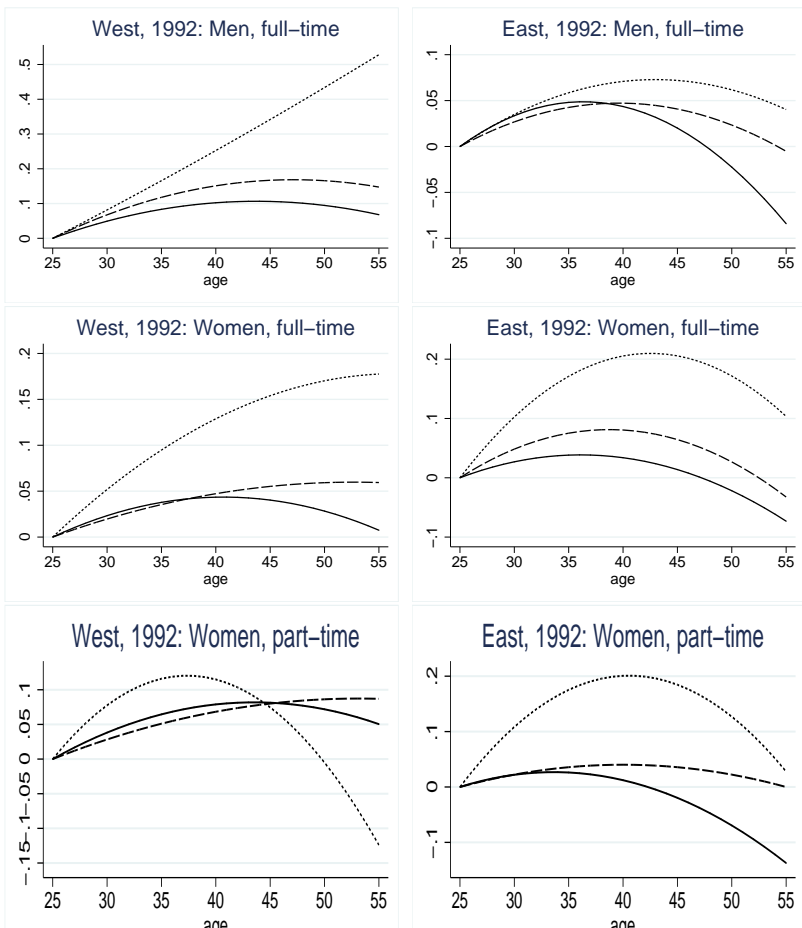

East, 1992: Women, part-time
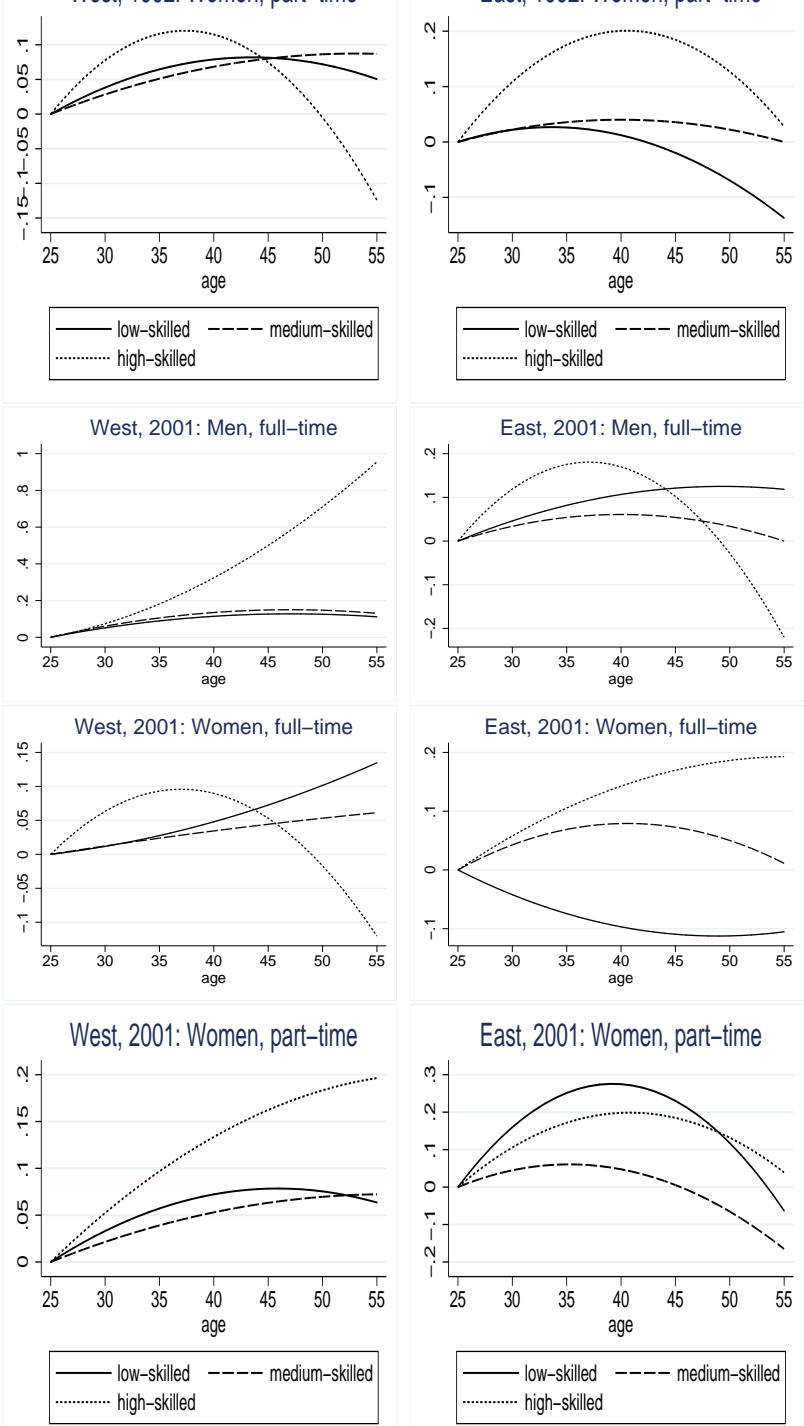

Results of censored median regressions. Solid lines: low-skilled; long dashed lines: medium-skilled; short dashed lines: high-skilled. Data source: IABS 1975-2001. 
Figure 16: Age-Earnings Profiles across the Wage Distribution, by Skill Groups: Men Working Full-Time
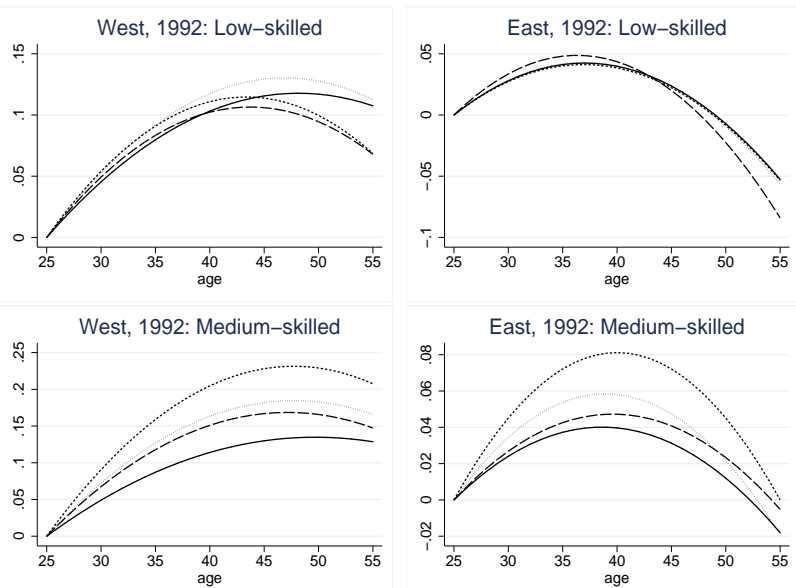

West, 1992: High-skilled
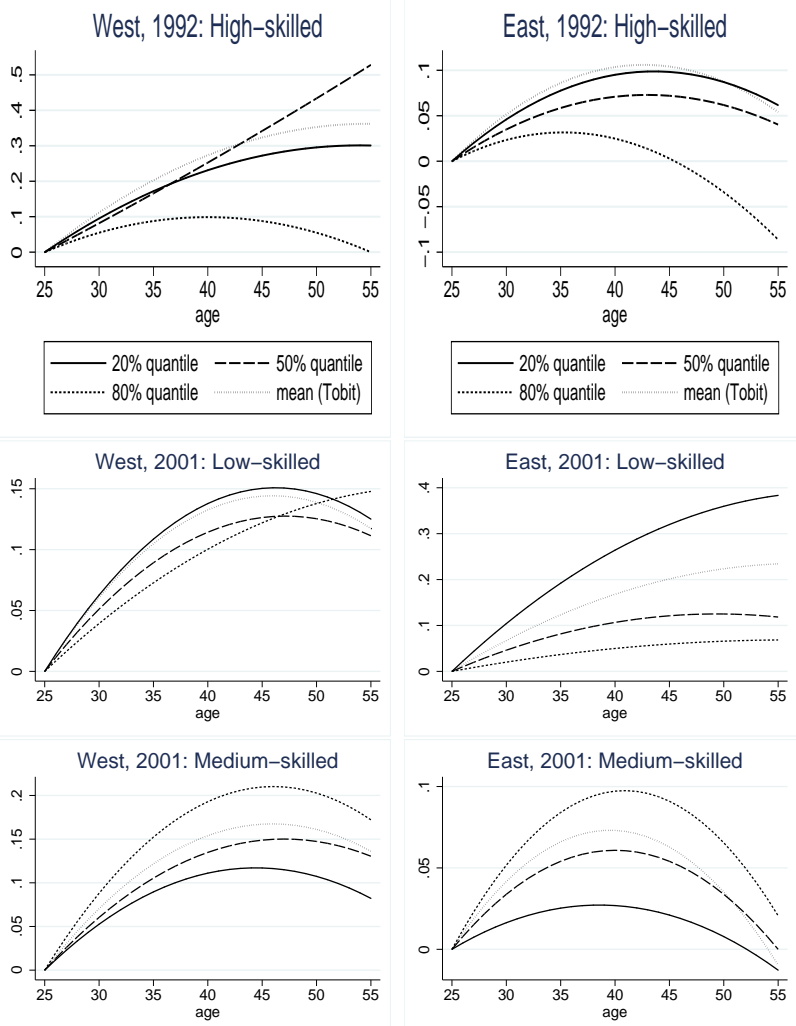

West, 2001: High-skilled
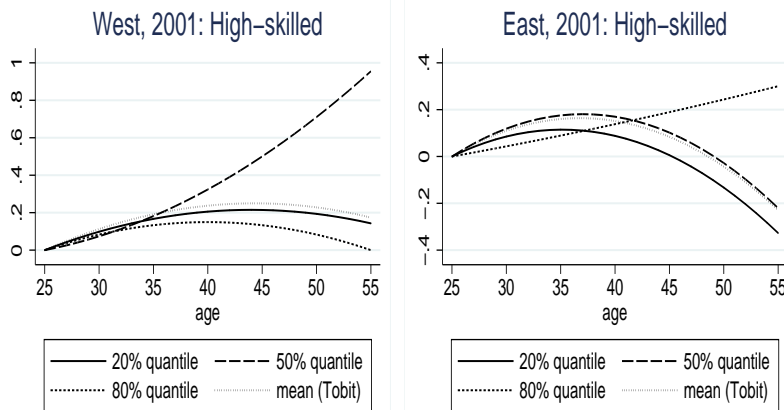

Results of censored quantile regressions. Solid lines: 20\% quantile; long dashed lines: $50 \%$ quantile; short dashed lines: 80\% quantile; dotted lines: mean (Tobit). Data source: IABS 1975-2001. 
Figure 17: Age Earnings Profiles across the Wage Distribution, by Skill Groups: Women Working Full-Time
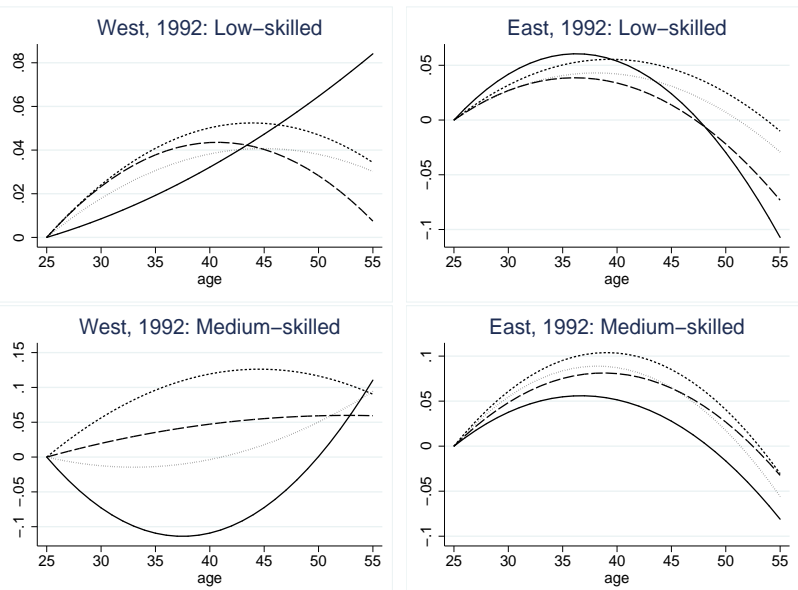

West, 1992: High-skilled
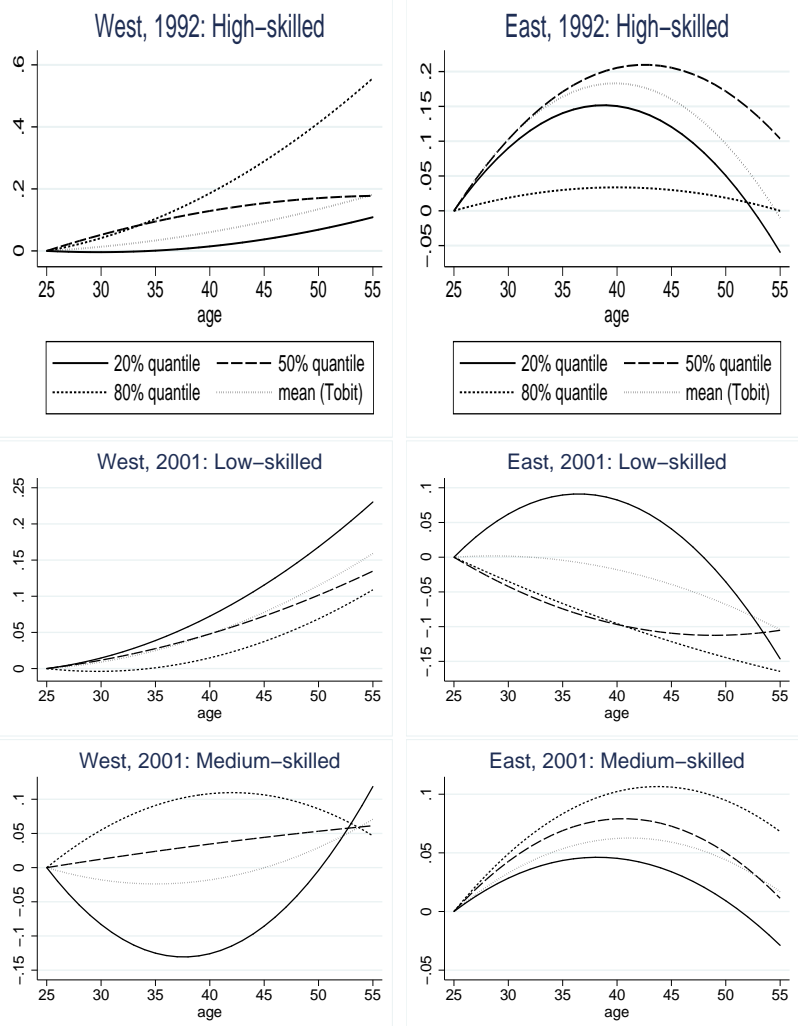

West, 2001: High-skilled
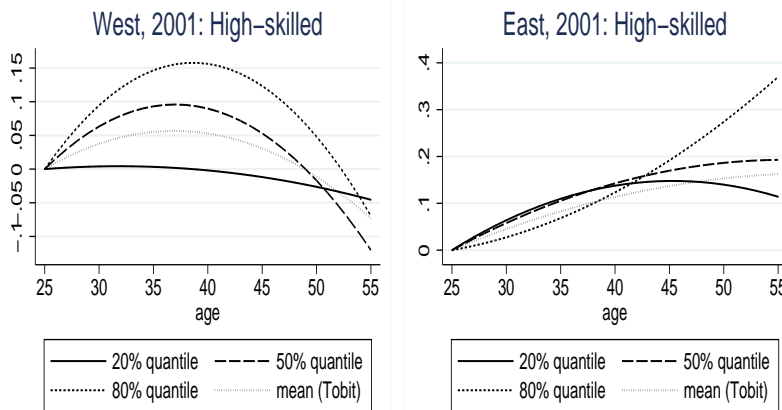

Results of censored quantile regressions. Solid lines: 20\% quantile; long dashed lines: $50 \%$ quantile; short dashed lines: 80\% quantile; dotted lines: mean (Tobit). Data source: IABS 1975-2001. 
Figure 18: Age Earnings Profiles across the Wage Distribution, by Skill Groups: Women Working Part-Time
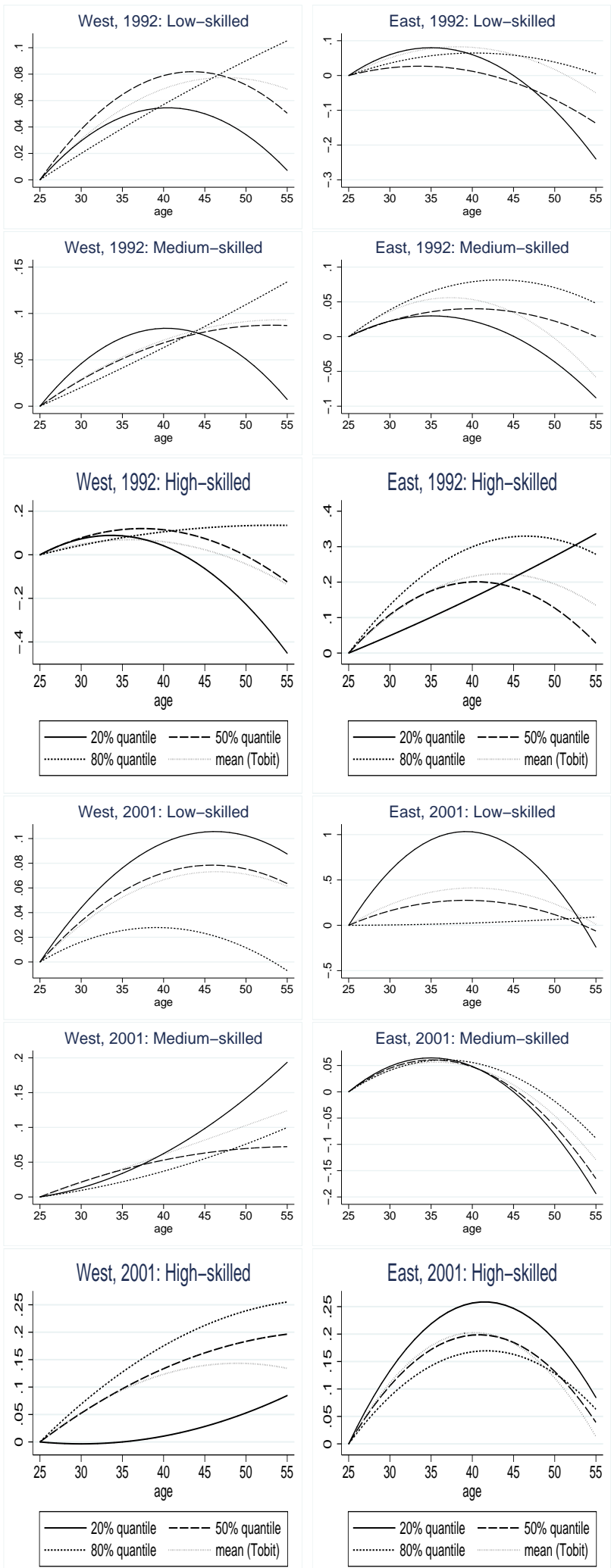

Results of censored quantile regressions. Solid lines: $20 \%$ quantile; long dashed lines: $50 \%$ quantile; short dashed lines: 80\% quantile; dotted lines: mean (Tobit). Data source: IABS 1975-2001. 
Table 4: Decomposition I: West-East Wage Differences Across the Distribution

Men Working Full-Time

\begin{tabular}{|c|c|c|c|c|c|c|c|c|c|c|}
\hline 1992 & 10 th & 20 th & 30 th & 40th & 50 th & 60 th & 70th & 80 th & 90 th & Tobit \\
\hline Observed gap & 0.546 & 0.570 & 0.579 & 0.574 & 0.576 & 0.590 & 0.604 & $\cdot$ & . & 0.587 \\
\hline Predicted gap & 0.555 & 0.569 & 0.573 & 0.578 & 0.579 & 0.595 & 0.607 & 0.614 & . & 0.578 \\
\hline Char. effect & -0.003 & 0.000 & 0.003 & 0.006 & 0.008 & 0.009 & 0.004 & 0.000 & . & -0.018 \\
\hline Coeff. effect & 0.557 & 0.570 & 0.570 & 0.572 & 0.571 & 0.585 & 0.603 & 0.614 & . & 0.596 \\
\hline \multicolumn{11}{|l|}{2001} \\
\hline Observed gap & 0.381 & 0.413 & 0.405 & 0.417 & 0.395 & 0.405 & 0.405 & 0.402 & . & 0.382 \\
\hline Predicted gap & 0.370 & 0.398 & 0.405 & 0.413 & 0.412 & 0.412 & 0.412 & 0.398 & . & 0.386 \\
\hline Char. effect & 0.010 & 0.007 & 0.010 & 0.012 & 0.021 & 0.024 & 0.024 & 0.022 & . & 0.008 \\
\hline Coeff. effect & 0.360 & 0.390 & 0.396 & 0.401 & 0.391 & 0.388 & 0.388 & 0.376 & . & 0.378 \\
\hline \multicolumn{11}{|c|}{ Women Working Full-Time } \\
\hline 1992 & 10 th & 20 th & 30 th & 40th & 50 th & 60 th & 70 th & 80 th & 90 th & Tobit \\
\hline Observed gap & 0.219 & 0.317 & 0.360 & 0.369 & 0.368 & 0.378 & 0.381 & 0.399 & . & 0.342 \\
\hline Predicted gap & 0.238 & 0.327 & 0.358 & 0.369 & 0.373 & 0.376 & 0.378 & 0.388 & . & 0.345 \\
\hline Char. effect & -0.086 & -0.086 & -0.079 & -0.076 & -0.066 & -0.056 & -0.056 & -0.059 & . & -0.073 \\
\hline Coeff. effect & 0.324 & 0.414 & 0.437 & 0.445 & 0.439 & 0.433 & 0.434 & 0.447 & . & 0.417 \\
\hline \multicolumn{11}{|l|}{2001} \\
\hline Observed gap & 0.150 & 0.254 & 0.276 & 0.234 & 0.177 & 0.146 & 0.143 & 0.161 & 0.171 & 0.179 \\
\hline Predicted gap & 0.171 & 0.249 & 0.263 & 0.227 & 0.192 & 0.164 & 0.157 & 0.158 & 0.156 & 0.179 \\
\hline Char. effect & -0.015 & -0.030 & -0.034 & -0.039 & -0.041 & -0.036 & -0.042 & -0.043 & -0.055 & -0.047 \\
\hline Coeff. effect & 0.186 & 0.279 & 0.297 & 0.266 & 0.233 & 0.200 & 0.199 & 0.201 & 0.211 & 0.226 \\
\hline \multicolumn{11}{|c|}{ Women Working Part-Time } \\
\hline 1992 & 10 th & 20 th & 30 th & 40 th & 50 th & 60 th & 70 th & 80 th & 90 th & Tobit \\
\hline Observed gap & 0.061 & 0.187 & 0.201 & 0.215 & 0.212 & 0.210 & 0.187 & 0.151 & 0.125 & 0.168 \\
\hline Predicted gap & 0.096 & 0.197 & 0.213 & 0.215 & 0.208 & 0.199 & 0.181 & 0.161 & 0.147 & 0.186 \\
\hline Char. effect & -0.049 & -0.038 & -0.028 & -0.016 & -0.015 & -0.013 & -0.017 & -0.018 & -0.033 & -0.016 \\
\hline Coeff. effect & 0.145 & 0.235 & 0.241 & 0.231 & 0.223 & 0.212 & 0.198 & 0.179 & 0.180 & 0.202 \\
\hline \multicolumn{11}{|l|}{2001} \\
\hline Observed gap & -0.043 & 0.000 & 0.000 & 0.000 & 0.000 & 0.000 & -0.018 & 0.000 & 0.013 & -0.013 \\
\hline Predicted gap & -0.063 & -0.020 & 0.000 & -0.010 & -0.004 & -0.009 & -0.017 & 0.003 & 0.008 & 0.003 \\
\hline Char. effect & -0.023 & -0.021 & -0.028 & -0.015 & -0.009 & -0.013 & -0.017 & -0.017 & -0.015 & -0.004 \\
\hline Coeff. effect & -0.040 & 0.001 & 0.028 & 0.005 & 0.006 & 0.004 & 0.000 & 0.020 & 0.024 & 0.007 \\
\hline
\end{tabular}

Nominal differences, evaluated at various percentiles. Tobit "observed" gaps estimated by Tobit regressions on a constant. · indicates censored deciles. Data source: IABS 1975-2001. 
Table 5: Decomposition II: Changes of the Wage Structure, 1992-2001

\begin{tabular}{|c|c|c|c|c|c|c|c|c|c|c|}
\hline & Men W & orking $\mathrm{F}$ & all-Time & & & & & & & \\
\hline West Germany & 10 th & 20 th & 30 th & 40 th & 50 th & 60 th & 70 th & 80 th & 90 th & Tobit \\
\hline Observed change & -0.075 & -0.038 & -0.023 & -0.010 & -0.006 & 0.016 & 0.030 & 0.051 & . & -0.004 \\
\hline Predicted change & -0.075 & -0.039 & -0.027 & -0.015 & 0.001 & 0.012 & 0.030 & 0.051 & . & 0.001 \\
\hline Char. effect & 0.010 & 0.013 & 0.013 & 0.023 & 0.032 & 0.037 & 0.045 & 0.052 & . & 0.036 \\
\hline Coeff. effect & -0.084 & -0.052 & -0.040 & -0.038 & -0.030 & -0.025 & -0.015 & -0.001 & . & -0.036 \\
\hline \multicolumn{11}{|l|}{ East Germany } \\
\hline Observed change & 0.001 & 0.031 & 0.062 & 0.058 & 0.087 & 0.112 & 0.140 & . & . & 0.112 \\
\hline Predicted change & 0.022 & 0.044 & 0.052 & 0.062 & 0.080 & 0.106 & 0.136 & 0.179 & . & 0.104 \\
\hline Char. effect & 0.012 & -0.013 & -0.015 & -0.013 & -0.007 & -0.003 & 0.006 & 0.013 & . & -0.011 \\
\hline Coeff. effect & 0.034 & 0.057 & 0.067 & 0.076 & 0.087 & 0.109 & 0.130 & 0.166 & . & 0.115 \\
\hline \multicolumn{11}{|c|}{ Women Working Full-Time } \\
\hline West Germany & 10 th & 20 th & 30 th & 40th & 50 th & 60 th & 70 th & 80 th & 90th & Tobit \\
\hline Observed change & -0.024 & 0.000 & -0.001 & 0.035 & 0.045 & 0.053 & 0.068 & 0.075 & 0.106 & 0.040 \\
\hline Predicted change & -0.017 & -0.009 & 0.008 & 0.027 & 0.043 & 0.053 & 0.065 & 0.082 & 0.103 & 0.032 \\
\hline Char. effect & 0.006 & 0.004 & 0.012 & 0.021 & 0.027 & 0.034 & 0.036 & 0.047 & 0.054 & 0.017 \\
\hline Coeff. effect & -0.023 & -0.013 & -0.004 & 0.007 & 0.016 & 0.019 & 0.029 & 0.035 & 0.049 & 0.015 \\
\hline \multicolumn{11}{|l|}{ East Germany } \\
\hline Observed change & -0.043 & -0.025 & -0.006 & 0.081 & 0.147 & 0.197 & 0.217 & 0.225 & . & 0.113 \\
\hline Predicted change & -0.038 & -0.019 & 0.015 & 0.081 & 0.137 & 0.177 & 0.197 & 0.224 & . & 0.110 \\
\hline Char. effect & -0.044 & -0.044 & -0.067 & -0.064 & -0.038 & -0.012 & 0.003 & 0.013 & . & -0.026 \\
\hline Coeff. effect & 0.006 & 0.025 & 0.082 & 0.144 & 0.175 & 0.190 & 0.195 & 0.212 & . & 0.136 \\
\hline \multicolumn{11}{|c|}{ Women Working Part-Time } \\
\hline West Germany & 10 th & 20 th & 30 th & 40 th & 50 th & 60 th & 70 th & 80 th & 90 th & Tobit \\
\hline Observed change & 0.112 & 0.054 & 0.051 & 0.065 & 0.068 & 0.091 & 0.104 & 0.114 & 0.111 & 0.079 \\
\hline Predicted change & 0.076 & 0.037 & 0.039 & 0.054 & 0.072 & 0.087 & 0.097 & 0.108 & 0.106 & 0.077 \\
\hline Char. effect & 0.011 & 0.025 & 0.021 & 0.024 & 0.026 & 0.031 & 0.026 & 0.034 & 0.030 & 0.024 \\
\hline Coeff. effect & 0.066 & 0.012 & 0.017 & 0.030 & 0.046 & 0.056 & 0.071 & 0.074 & 0.076 & 0.053 \\
\hline \multicolumn{11}{|l|}{ East Germany } \\
\hline Observed change & 0.127 & 0.152 & 0.163 & 0.191 & 0.191 & 0.212 & 0.220 & 0.176 & 0.134 & 0.173 \\
\hline Predicted change & 0.147 & 0.166 & 0.163 & 0.190 & 0.195 & 0.206 & 0.207 & 0.178 & 0.156 & 0.172 \\
\hline Char. effect & 0.020 & 0.020 & 0.000 & 0.017 & 0.005 & 0.007 & 0.017 & 0.013 & 0.008 & 0.008 \\
\hline Coeff. effect & 0.127 & 0.146 & 0.163 & 0.173 & 0.190 & 0.198 & 0.190 & 0.165 & 0.149 & 0.164 \\
\hline
\end{tabular}

Real differences, evaluated at various percentiles. Tobit "observed" gaps estimated by Tobit regressions on a constant. · indicates censored deciles. Data source: IABS 1975-2001. 